\title{
Observations of martian gullies and constraints on potential formation mechanisms II. The northern hemisphere
}

\author{
Jennifer L. Heldmann ${ }^{\mathrm{a}, *}$, Ella Carlsson ${ }^{\mathrm{b}, \mathrm{c}}$, Henrik Johansson ${ }^{\mathrm{b}}$, Michael T. Mellon ${ }^{\mathrm{d}}$, Owen B. Toon ${ }^{\mathrm{e}}$ \\ a NASA Ames Research Center, Space Science Division, Moffett Field, CA 94035, USA \\ ${ }^{\mathrm{b}}$ Division of Physics, Luleå University of Technology, SE-97187 Luleå, Sweden \\ ${ }^{\mathrm{c}}$ Swedish Institute of Space Physics, Box 812, SE-98128 Kiruna, Sweden \\ ${ }^{\mathrm{d}}$ University of Colorado, Laboratory for Atmospheric and Space Physics, Boulder, CO 80309, USA \\ ${ }^{e}$ University of Colorado, Laboratory for Atmospheric and Space Physics, Program in Atmospheric and Oceanic Sciences, Boulder, CO 80309, USA
}

Received 12 May 2006; revised 9 November 2006

Available online 3 January 2007

\begin{abstract}
The formation process(es) responsible for creating the observed geologically recent gully features on Mars has remained the subject of intense debate since their discovery. We present new data and analysis of northern hemisphere gullies from Mars Global Surveyor data which is used to test the various proposed mechanisms of gully formation. We located 137 Mars Orbiter Camera (MOC) images in the northern hemisphere that contain clear evidence of gully landforms and analyzed these images in combination with Mars Orbiter Laser Altimeter (MOLA) and Thermal Emission Spectrometer (TES) data to provide quantitative measurements of numerous gully characteristics. Parameters we measured include apparent source depth and distribution, vertical and horizontal dimensions, slopes, orientations, and present-day characteristics that affect local ground temperatures. Northern hemisphere gullies are clustered in Arcadia Planitia, Tempe Terra, Acidalia Planitia, and Utopia Planitia. These gullies form in craters (84\%), knobby terrain (4\%), valleys (3\%), other/unknown terrains (9\%) and are found on all slope orientations although the majority of gullies are equator-facing. Most gullies (63\%) are associated with competent rock strata, 26\% are not associated with strata, and $11 \%$ are ambiguous. Assuming thermal conductivities derived from TES measurements as well as modeled surface temperatures, we find that $95 \%$ of the gully alcove bases with adequate data coverage lie at depths where subsurface temperatures are greater than $273 \mathrm{~K}$ and $5 \%$ of the alcove bases lie within the solid water regime. The average alcove length is $470 \mathrm{~m}$ and the average channel length is $690 \mathrm{~m}$. Based on a comparison of measured gully features with predictions from the various models of gully formation, we find that models involving carbon dioxide, melting ground ice in the upper few meters of the soil, dry landslide, and surface snowmelt are the least likely to describe the formation of the martian gullies. Although some discrepancies still exist between prediction and observation, the shallow and deep aquifer models remain as the most plausible theories. Interior processes involving subsurface fluid sources are generally favored over exogenic processes such as wind and snowfall for explaining the origin of the martian gullies. These findings gleaned from the northern hemisphere data are in general agreement with analyses of gullies in the southern hemisphere [Heldmann, J.L., Mellon, M.T., 2004. Icarus 168, 285-304].
\end{abstract}

Published by Elsevier Inc.

Keywords: Mars; Geological processes

\section{Introduction}

The Mars Global Surveyor (MGS) Mars Orbiter Camera (MOC) revealed the presence of geologically young small-scale features resembling terrestrial water-carved gullies in 2000

\footnotetext{
* Corresponding author. Fax: +16506046779.

E-mail address: jheldmann@mail.arc.nasa.gov (J.L. Heldmann).
} (Malin and Edgett, 2000) and initial research mostly concen- 
trated on studying gully features in the southern hemisphere. Gullies have been previously reported in the northern hemisphere (Edgett et al., 2003; Heldmann et al., 2005a) and in this work we systematically analyze these northern hemisphere gullies to (1) determine their physical and dimensional properties, (2) place constraints on potential mechanisms of formation, and (3) compare and contrast the northern hemisphere gullies with their southern hemisphere counterparts.

Gullies in both the northern and southern hemisphere display similar morphologies and age relations. The superposition of the gullies on geologically young surfaces such as dunes and polygons as well as a general scarcity of superposed impact craters indicate the relative youth of the gullies, suggesting that the gullies formed within the past few million years (Malin and Edgett, 2000, 2001; Edgett et al., 2003). These features exhibit a characteristic morphology indicative of fluid-type erosion and liquid water has been suggested as a likely fluid. However, since liquid water is currently unstable on the surface of Mars with respect to boiling and freezing, the relatively young geologic age of these gullies has been perceived as a paradox. Heldmann et al. (2005b) have shown, however, that the formation of the gullies is consistent with simultaneous freezing and boiling of liquid water on the martian surface under current martian environmental conditions. The precise gully formation mechanism remains controversial, though, and numerous models for a source of water have been proposed, along with other potential erosional agents such as dry debris and $\mathrm{CO}_{2}$. Here we compare the proposed models with numerous observations of the physical and dimensional properties of these gully features. Our goal is to better constrain the hypothesized models of gully formation and to support future modeling efforts.

Numerous models have been proposed which invoke various physical processes, as well as various agents of erosion, to explain the origin of the martian gullies and the origin of the erosive agents. Musselwhite et al. (2001) proposed that an aquifer could provide liquid $\mathrm{CO}_{2}$ to carve the gullies. Malin and Edgett (2000) and Mellon and Phillips (2001) suggested that a shallow aquifer of liquid water could feed the gully systems, while Gaidos (2001) argued for a deep water aquifer. Costard et al. (2002) suggested that melting shallow ground ice is the source of the water. Gilmore and Phillips (2002) argue for the presence of an aquiclude which drives meltwater from the nearsurface ice towards the gully sites. Lee et al. (2002), Hartmann (2002) and Christensen (2003) suggested that the gullies may be formed by liquid water from dissipating snowpacks. In addition, Treiman (2003) proposed that mass-wasting is also a candidate mechanism of gully formation.

Any viable model of the formation of these gullies, the type of erosive fluid, and its source, must be consistent with the observational constraints. In this work we combine MGS MOC, Mars Orbiter Laser Altimeter (MOLA), and Thermal Emission Spectrometer (TES) measurements for 137 MOC gully images in the northern hemisphere to determine systematic trends in these data and test the various proposed mechanisms for the formation of the gully features. In subsequent sections we describe the method of data collection as well as measurements of various gully parameters including apparent source depth and distribution, vertical and horizontal dimensions, slopes, orientations, and properties controlling the local thermal regimes. These observed gully properties are analyzed for implications relevant to gully formation and the results are then compared with several proposed theories of gully formation to place additional constraints on these mechanisms. We also compare these findings with results obtained for the southern hemisphere to determine any differences and/or similarities between the two populations of gullies in the northern and southern hemispheres of Mars.

\section{Methodology}

We utilized MOC narrow-angle images from mission phases AB1 through R15 (September 1997 through March 2004) and systematically examined 13,710 of these images over latitudes $30^{\circ} \mathrm{N}$ to $90^{\circ} \mathrm{N}$ for the presence of gullies. Gullies were geomorphically identified primarily based on the presence of distinctive incised V-shaped channels emanating from an eroded alcove. Debris aprons further confirm the positive identification of gully features, but were sometimes cut off by the finite image size. Images containing potential gully landforms with ambiguous or unclear evidence of incised channels and alcovechannel morphology were discarded. For example, gully-like features found on crater central peaks and sand dunes were not included due to significant deviations from this requisite morphology (Heldmann et al., 2004). Also, many gully locations have been imaged by MOC multiple times and so duplicate images of the same gully systems were not used here. A total of 137 MOC images containing well-defined gully features in the northern hemisphere of Mars were found and used in this analysis.

The MOC data were radiometrically calibrated and geometrically transformed to an equal-area sinusoidal map projection using ISIS (Integrated Software for Images and Spectrometers) (Kirk et al., 2001a). For each image where a simultaneous MOLA track was taken with the MOC image, an elevation map was assembled using all MOLA ground tracks over and around the area to maximize the density of elevation data in each gully locale. Typical MOLA coverage was approximately 10 MOLA tracks per MOC narrow angle image. MOC and MOLA databases were co-registered by aligning the datasets based on the spacecraft clock time and then calculating the resultant difference in geographic coordinates. A final correction was applied to account for the boresight offset between MOC and MOLA (Kirk et al., 2001a). Bilinear interpolation was applied to the irregularly gridded data before contouring. These MOLA elevation data were then used to create a topographic map of the region.

Linear distances were determined directly from the ISISprojected MOC image and elevations were extracted from the topographic map. The schematic in Fig. 1 shows the horizontal and vertical gully parameters that were measured. Throughout this paper, an individual gully is composed of one alcove with one or more channel(s) originating from the alcove base. A gully system is composed of numerous gullies which emanate from the same slope face, occur side by side along the 


\section{Top View}

Ridge

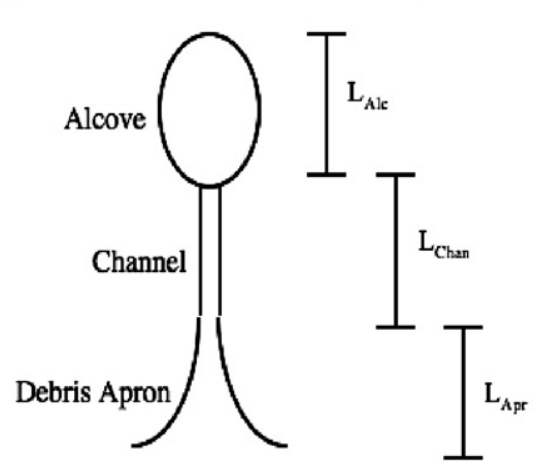

\section{Side View}

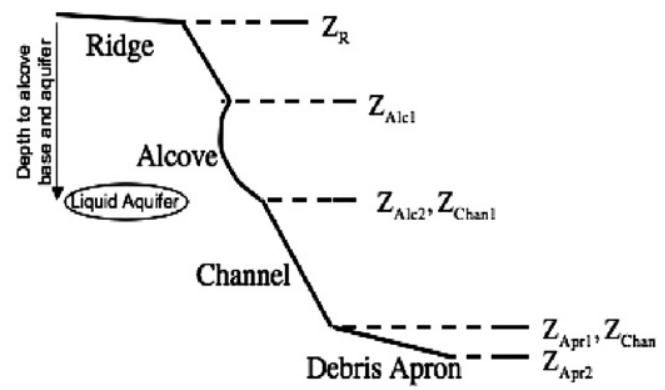

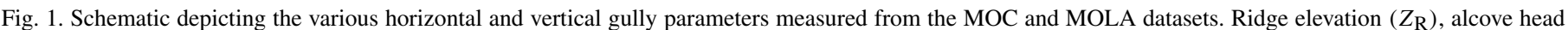

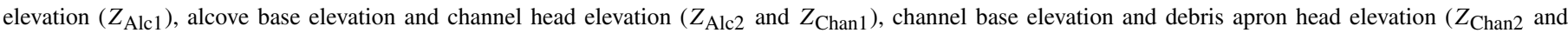

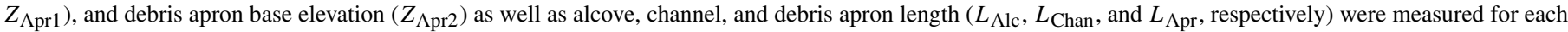
gully with adequate data coverage of each feature. The schematic also shows the location of a proposed liquid aquifer.

slope, and have similar vertical and horizontal dimensions. A gully image refers to a MOC image which has clear evidence for at least one gully; each MOC image may contain numerous gullies and/or gully systems. Depending on clipping along image boundaries not all properties could be measured for each individual gully. Up to 13 individual gullies were measured for each gully system; variability of horizontal and vertical gully parameters was found to be small within a gully system, thus 13 individual gullies well represented the gully system. This variability increases when comparing gullies among different systems.

The elevation of the ridge above each gully alcove (assuming the ridge was not cut off in the MOC image due to the finite image size), $Z_{\mathrm{R}}$, was measured directly above each gully alcove head. The break in slope between the plateau and the slope surface containing the gullies is primarily determined by the elevation data. The break in slope is further verified by brightness differences in the MOC image between the flat upslope plateau and the slope containing the gullies.

The elevation of the alcove head $\left(Z_{\mathrm{Alc} 1}\right)$ and base $\left(Z_{\mathrm{Alc} 2}\right)$ was also measured. The identification of an alcove was based on the presence of an eroded theater-shaped depression from which emanate a system of roughly V-shaped channels. The alcove base was marked by the location where the alcove tapered to form a narrower, more condensed network of channels. The alcove base elevation $\left(Z_{\mathrm{Alc} 2}\right)$ is also the channel head elevation $\left(Z_{\text {Chan1 } 1}\right)$, unless otherwise noted.

The debris apron begins at the transition point where channels are no longer prominent and instead the terrain transitions into a widened fan with less relief (i.e., lack of $\mathrm{V}$-shaped channels). The debris apron head elevation $\left(Z_{\mathrm{Apr} 1}\right)$ is also the channel base elevation $\left(Z_{\mathrm{Chan} 2}\right)$, unless otherwise noted. The elevation of the debris apron base $\left(Z_{\mathrm{Apr} 2}\right)$ at its furthest visible location from the debris apron head was measured as well.

The horizontal extents of the alcoves $\left(L_{\mathrm{Alc}}\right)$, channels $\left(L_{\mathrm{Chan}}\right)$, and debris aprons $\left(L_{\mathrm{Apr}}\right)$ were also measured for each gully. Lengths were measured directly from the MOC images and therefore along-slope lengths may be slightly longer than reported here since these features are found on sloped terrain. The length of the alcoves was measured from the alcove head to the alcove base. Channel lengths were measured from the alcove base to the beginning of the debris apron or until the channel ended if there was no clear debris apron. The horizontal extent of the debris apron was measured from the head of the apron to the debris apron end.

The range of gully orientations was measured for each gully system within an image. Gully orientations were measured from the map projected MOC images along the gully axis formed by the alcove-channel-debris apron structure with respect to the geographic pole.

We estimate that elevations derived from MOLA data and lengths derived from MOC data are both typically accurate to $\sim 10 \mathrm{~m}$. The vertical accuracy of MOLA is $1.5 \mathrm{~m}$ (Zuber et al., 1992) and elevation maps were created at $50 \mathrm{~m}$ contour intervals; smaller contour intervals proved impractical due to the high density of contours obscuring the gully slopes. The horizontal accuracy of MOLA is $\sim 100 \mathrm{~m}$ which is smaller than the 160 m diameter MOLA footprint (Zuber et al., 1992; Kirk et al., 2001b). Hence, our elevation uncertainty is mainly an artifact of our contour map interpolation. Horizontal length uncertainties are governed by the lowest image resolution of $\sim 10 \mathrm{~m} /$ pixel.

TES thermal inertia and albedo measurements are valuable in characterizing the surface and subsurface temperature environment, and were extracted from $1 / 20^{\circ}$ resolution binned maps (Mellon et al., 2000, 2002) for each MOC image containing gullies. TES resolution is significantly lower than the scale of individual gullies; a single TES footprint is about the same as the width of an entire MOC image. Thermal inertia and albedo values are therefore representative of the general terrain surrounding the gully systems. 


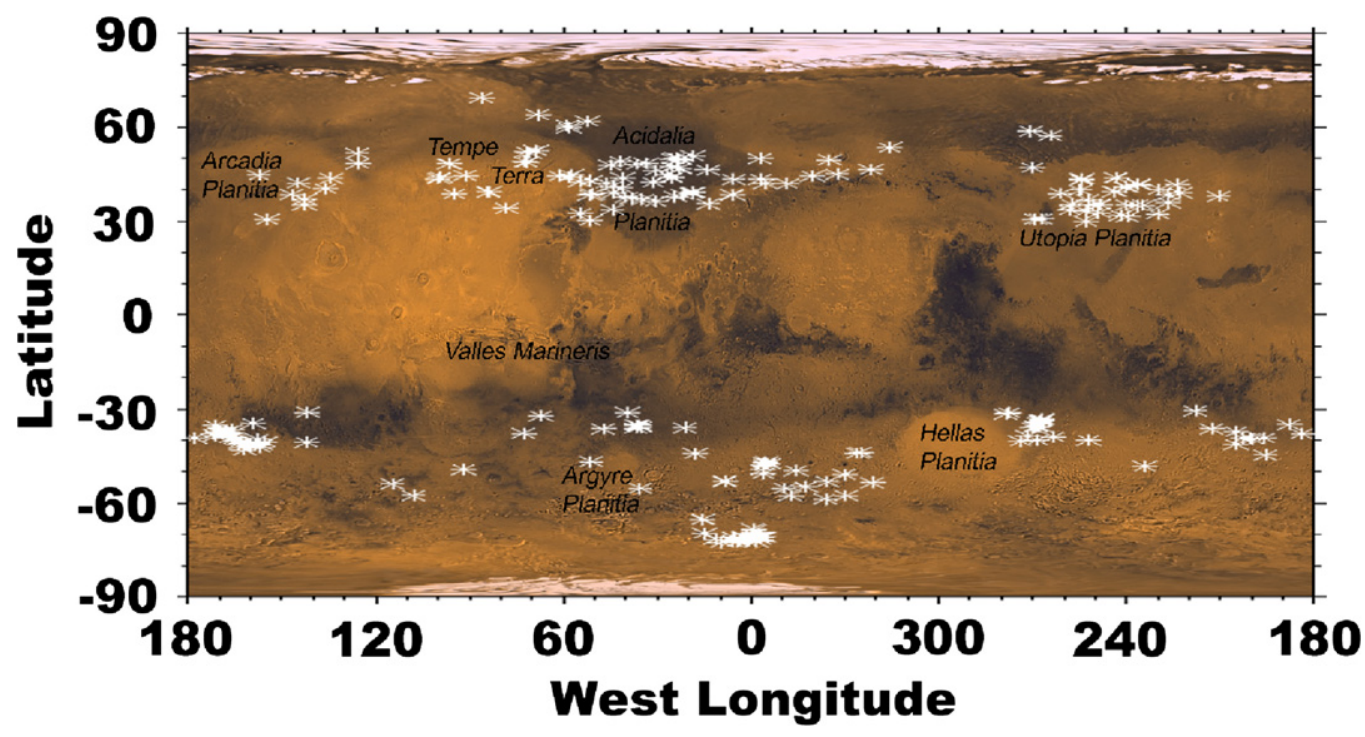

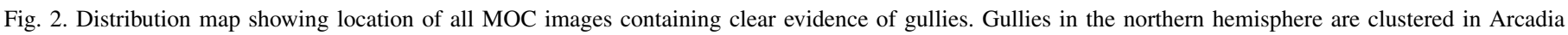
Planitia, Tempe Terra, Acidalia Planitia, and Utopia Planitia. Location of southern hemisphere gullies from Heldmann and Mellon (2004).

\section{Observations}

In this section we present our observations of gully dimensions and properties for the northern hemisphere. We examine the variation of these properties to look for specific trends that may help constrain the process by which gullies form.

Martian gullies occur in a wide variety of terrain types. For the northern hemisphere, $84 \%$ of the gullies form in craters, $4 \%$ in knobby terrain, $3 \%$ in valleys, $7 \%$ in other terrain types, and $2 \%$ in unknown terrain (no wide angle MOC context image). Most gullies (63\%) are clearly associated with competent rock strata, $26 \%$ are not associated with strata, and $11 \%$ are ambiguous cases (unclear imagery and/or the alcoves are clipped by the finite image size). Where gullies emanate from more competent strata, the alcoves are not always associated with the uppermost layer but may be embedded within a sequence of strata that are morphologically indistinguishable.

Fig. 2 shows the geographic location of the 137 gully images located in the northern hemisphere. Gully locations in the southern hemisphere are from Heldmann and Mellon (2004). Northern hemisphere gullies are clustered in Arcadia Planitia, Tempe Terra, Acidalia Planitia, and Utopia Planitia. These trends of regional clustering appear to be real and not a result of biased imaging at particular locations given the relatively even distribution of MOC narrow-angle images within the studied latitude range.

The latitudinal distribution of gully images is shown in Fig. 3. As latitude increases from $30^{\circ}$ to $\sim 45^{\circ} \mathrm{N}$ the number of gully images also increases. From $\sim 45^{\circ}$ to $72^{\circ} \mathrm{N}$ the number of gully images declines with the exception of a spike in the occurrence of gullies between $48^{\circ}-51^{\circ} \mathrm{N}$. MOC images were searched up through $90^{\circ} \mathrm{N}$ but no gullies were found at these higher latitudes above $72^{\circ} \mathrm{N}$.

The distribution of the absolute elevation of the gully alcoves as a function of latitude is shown in Fig. 4 relative to the global elevation trends. The gullies span a range in elevations from

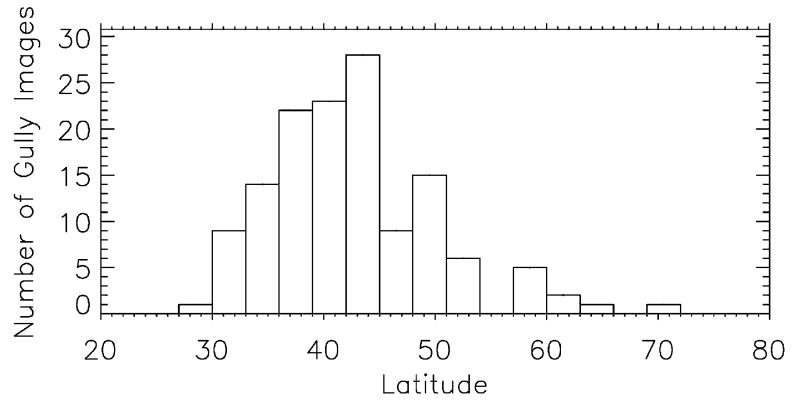

Fig. 3. Histogram showing the number of MOC images containing clear evidence of gullies per $3^{\circ}$ latitude bin.

$+0.8 \mathrm{~km}$ to $-5.4 \mathrm{~km}$. The gullies do not display a distinct preference for any specific elevation since they tend to be found at the average elevations of Mars as well as higher elevations where such terrains are available (e.g., $\left.32^{\circ}-50^{\circ} \mathrm{N}\right)$.

Most gullies (95\%) are located at elevations below the $0 \mathrm{~m}$ datum on Mars as the majority of the northern lowlands (where the gullies are located) is below $0 \mathrm{~m}$. Poleward of $50^{\circ} \mathrm{N}$ gullies are not observed at elevations higher than $-2.2 \mathrm{~km}$, possibly because of the lack of terrains at higher elevations in these regions as shown in Fig. 4. The minimum gully elevation poleward of $50^{\circ} \mathrm{N}$ is $-4.9 \mathrm{~km}$.

The depth from the overlying ridge to each gully alcove base $\left(Z_{R}-Z_{\text {Alc2 }}\right)$ was measured for each alcove where coalignment of the MOC and MOLA data was possible given the existence of a simultaneous MOLA track taken with the MOC image. Forty-two alcove base depths were measured from 10 individual MOC images and these values ranged from $100 \mathrm{~m}$ to $550 \mathrm{~m}$ with an average depth of $350 \mathrm{~m}$. Visual inspection of the remaining MOC images (without the coaligned MOLA data) indicate that (1) the vast majority of alcove base depths likely fall within this measured range and (2) most alcoves form in the upper reaches of the encompassing slope.

The latitudinal distributions of alcove, channel, and debris apron lengths ( $\left.L_{\mathrm{Alc}}, L_{\mathrm{Chan}}, L_{\mathrm{Apr}}\right)$ are shown in Fig. 5. Gullies 
at each latitude have a wide range of alcove, channel, and debris apron lengths with no strong trends with respect to latitude. Alcove lengths span a range from $0.10-1.6 \mathrm{~km}$ with an average value of $0.469 \mathrm{~km}$. Channel lengths show the most variance with lengths ranging from $0.192-2.65 \mathrm{~km}$ and the average is $0.688 \mathrm{~km}$. Debris aprons range from $0.120-0.970 \mathrm{~km}$ in length with an average value of $0.387 \mathrm{~km}$.

Fig. 6 shows the relationship between alcove and channel lengths for each individual gully. The majority of gullies $(66 \%)$ have longer channels than alcoves. There is only once instance of equal alcove and channel length (located at $38.38^{\circ} \mathrm{N}$ ). The ratio of channel length to alcove length varies from 0.34 (alcove length $=1.6 \mathrm{~km}$, channel length $=0.54 \mathrm{~km}$ ) to 5.0 (alcove length $=0.18 \mathrm{~km}$, channel length $=0.90 \mathrm{~km}$ ) with an average of 1.76 .

The orientation of the gullies is shown with respect to latitude in Fig. 7. An inherent bias may exist in the orientation

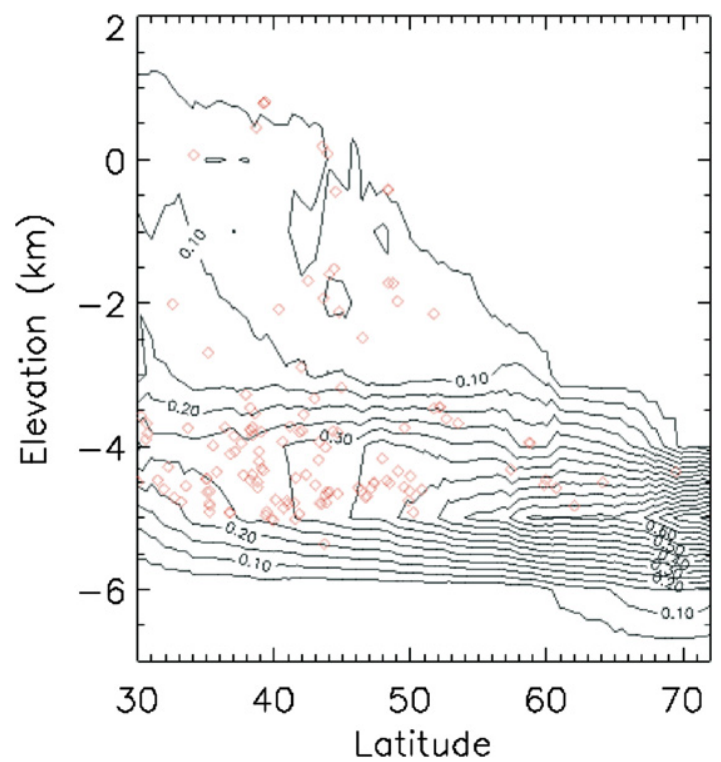

Fig. 4. Gully elevations (red diamonds) compared with the global elevation distribution in the northern latitudes. Contours show the zonal distribution of elevations for each $1^{\circ}$ latitude bin at $1 \mathrm{~km}$ intervals. Contour values are the fraction of each elevation bin per latitude zone; contour intervals are 0.05 . results due to MOC targeting and the common saturation of more brightly lit equatorward-facing slopes in MOC images which makes gully identification difficult. In spite of potential biases, we find that gullies occur on all orientations of slopes. Gullies are fairly evenly divided between poleward and equatorward facing orientations at the lower latitudes $\left(30^{\circ}-44^{\circ} \mathrm{N}\right)$ with a slight preference for equatorward facing slopes. At the midlatitudes $\left(44^{\circ}-58^{\circ} \mathrm{N}\right)$ the gullies are almost exclusively found on equatorward facing slopes. Then again at the higher latitudes $\left(58^{\circ}-72^{\circ} \mathrm{N}\right)$ the gullies are again fairly evenly divided between poleward and equatorward facing orientations. Overall, more gullies are found on equatorward facing slopes. This result is consistent with the findings of Edgett et al. (2003) which state that "In the northern hemisphere, more gullies face south than north." Gullies also show a wide range in the east-west orientation component, so the equatorward or poleward preference of gullies at any latitude should not be overemphasized.

The thermal inertia and albedo of the regions in and around gullies are compared with the general thermal inertia and albedo distributions of terrain between $30^{\circ}$ and $72^{\circ} \mathrm{S}$ in Fig. 8 . The gullies tend to be found in regions of lower thermal inertia and higher albedo relative to the global thermal inertia and albedo trends.

Most alcoves are found on slope angles that are less than the angle of repose (Fig. 9). The average alcove slope is $28^{\circ}$ with a standard deviation of $9^{\circ}$. About 45 and $46 \%$ of alcove slopes are within and below the range of angle of repose, respectively. Of the values outside of this range, most $(83 \%)$ are below the lower limit on the angle of repose.

The MOC data also reveals several additional interesting geomorphic characteristics of northern hemisphere gullies which may be important for understanding the formation history of these gully systems. These observations include the relation to superposed impact craters, associations with ice features, and the eroded appearance of the gully features.

First, there are several examples of gullies with superposed impact craters. Fig. 10 shows a gully system with small impact craters overlain on top of the gully features. Small impact features were observed on $20 \%$ of the gully systems in this study.
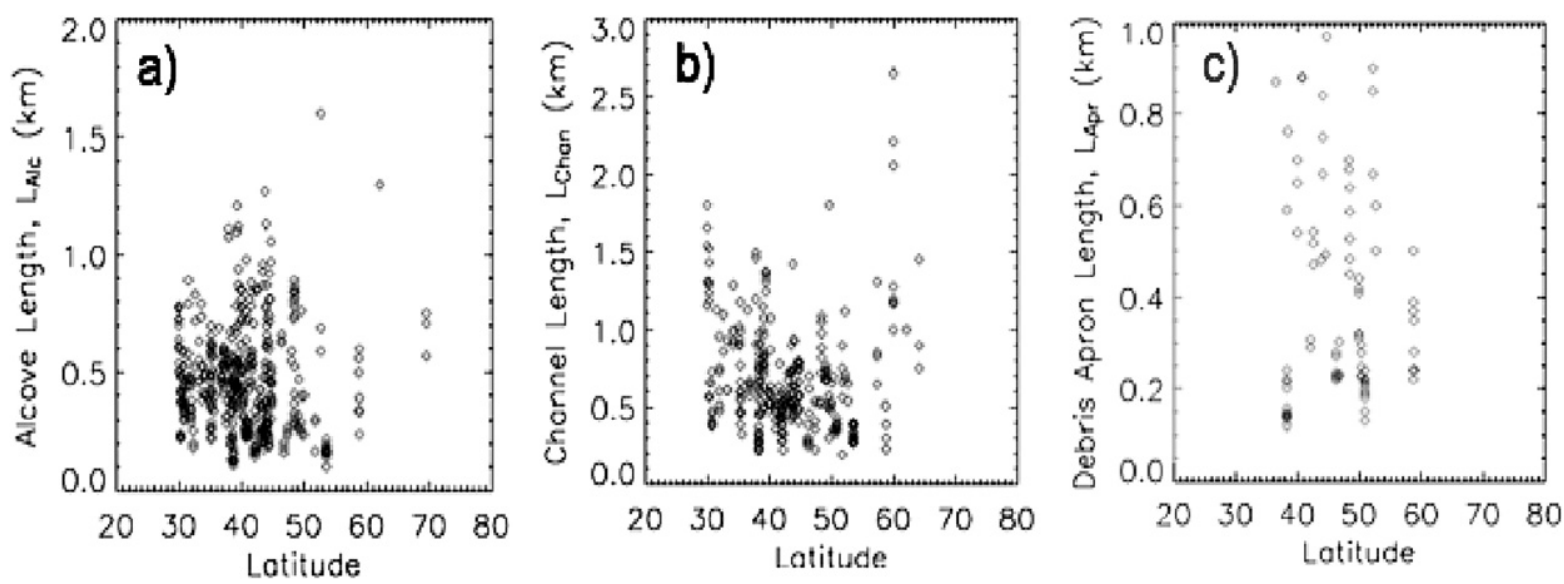

Fig. 5. Horizontal alcove length $\left(L_{\mathrm{Alc}}\right)$, channel length $\left(L_{\mathrm{Chan}}\right)$, and debris apron length $\left(L_{\mathrm{Apr}}\right)$ of each gully versus latitude. 
Gullies in the northern hemisphere are also sometimes associated with ice-related morphologies. There are several such examples of this relationship with the coexisting morphologies indicative of ice activity including pasted-on material, lobate apron features, and associations with patterned ground, rampart craters, and other ice-related morphologies.

Fig. 11 shows the pasted-on terrain first reported by Christensen (2003) in the southern hemisphere. It has been argued that this material is remnant ice/snow covered by a layer of dust which inhibits the water ice from rapidly sublimating away into the martian atmosphere and allows for heating and subsequent melting of the snowpack (Christensen, 2003).

Gullies can also be found associated with features which suggest the presence of ice in the near surface at some time. For

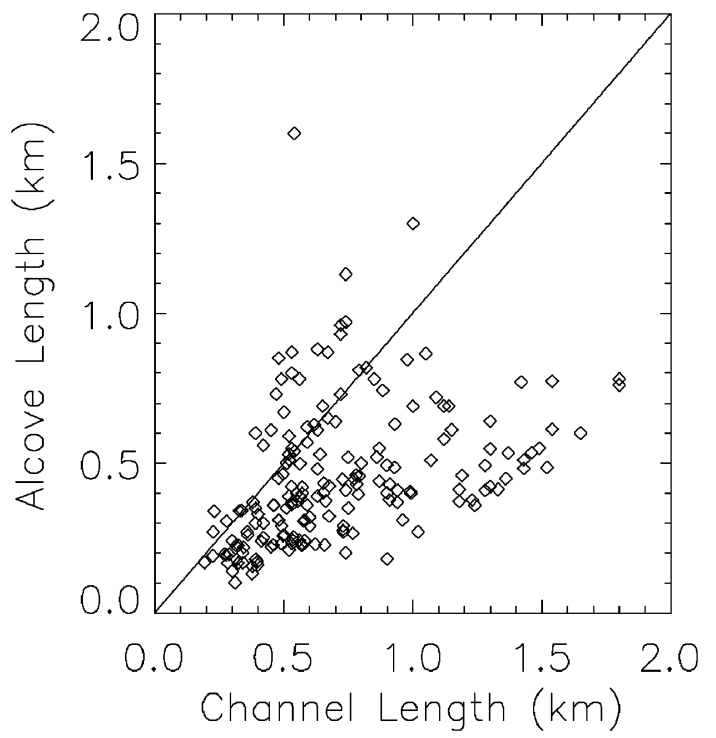

Fig. 6. Horizontal alcove length $\left(L_{\text {Alc }}\right)$ versus horizontal channel length $\left(L_{\text {Chan }}\right)$. Generally longer alcoves are associated with longer channels.

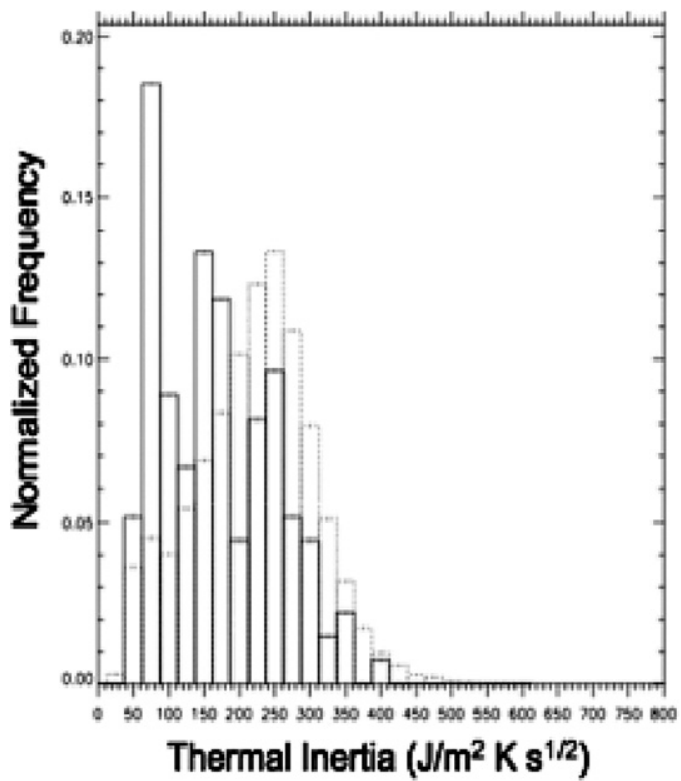

example, patterned ground and rampart craters associated with gully features are rare but exist nonetheless. Fig. 12a shows a rampart crater with lobate ejecta; gullies are found on the crater
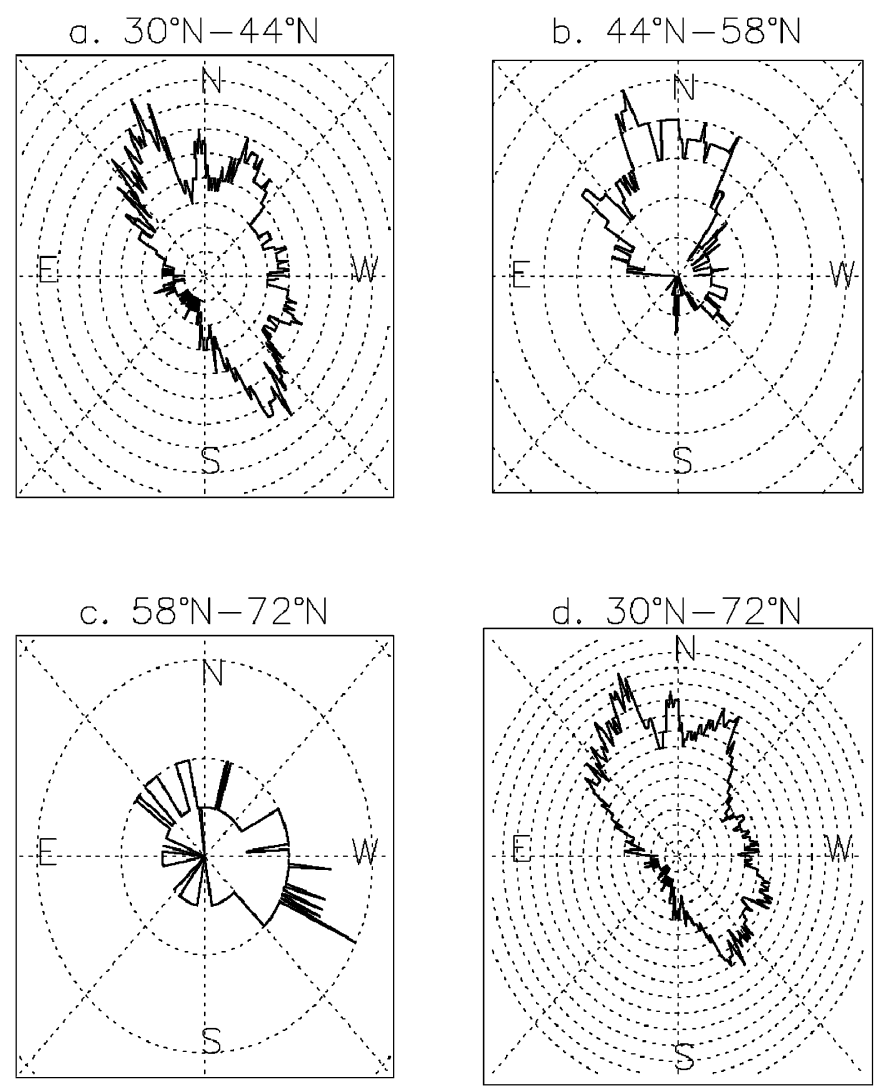

Fig. 7. The orientation of the martian gully systems are plotted for three latitude bins $\left(30^{\circ}\right.$ to $44^{\circ} \mathrm{N}, 44^{\circ}$ to $58^{\circ} \mathrm{N}, 58^{\circ}$ to $\left.72^{\circ} \mathrm{N}\right)$ as well as for all latitudes $\left(30^{\circ}\right.$ to $72^{\circ} \mathrm{N}$ ). The labels "N," "S," "E," and "W" on each orientation plot indicate gullies that are on north, south, east, and west slopes, respectively. Contours are in intervals of two gullies within each angle bin of $1^{\circ}$.

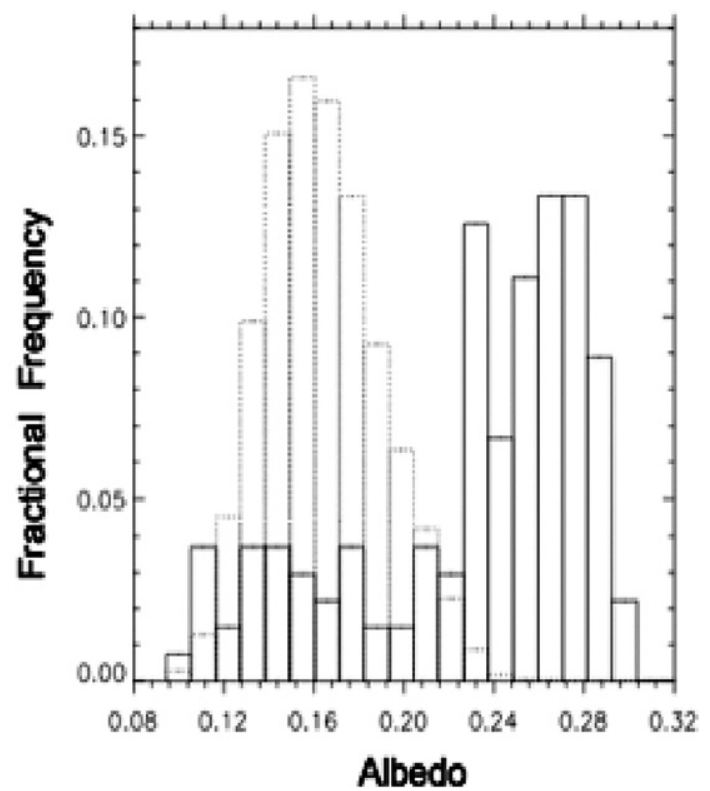

Fig. 8. Histogram of the thermal inertia and albedo in regions containing gullies (solid line) compared with the general distribution of thermal inertia (dotted line) for all terrains between $30^{\circ}-90^{\circ} \mathrm{N}$ 


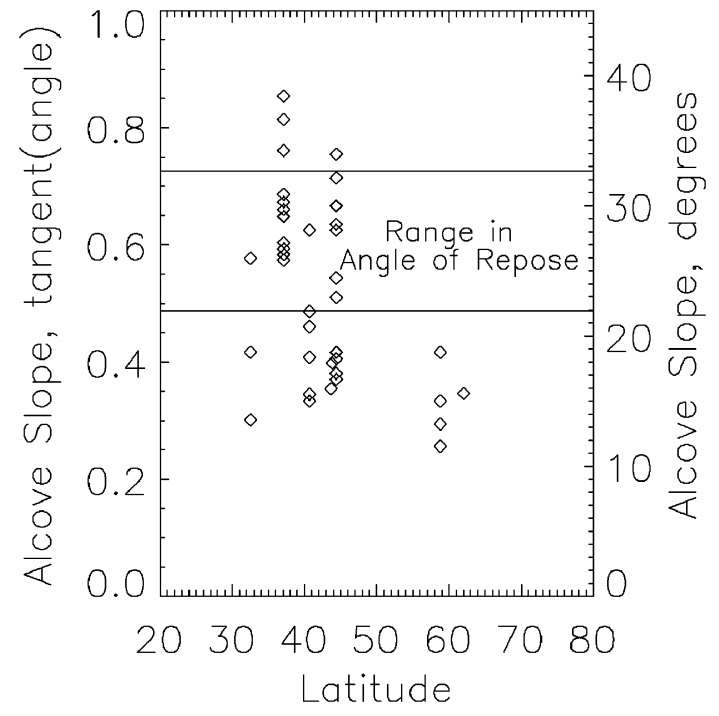

Fig. 9. Gully alcove slopes compared with the angle of repose. Alcove slopes are determined by dividing the change in vertical gully alcove elevation $\left(Z_{\mathrm{Alc} 1}-Z_{\mathrm{Alc} 2}\right)$ by the horizontal gully alcove length $\left(L_{\mathrm{Alc}}\right)$.

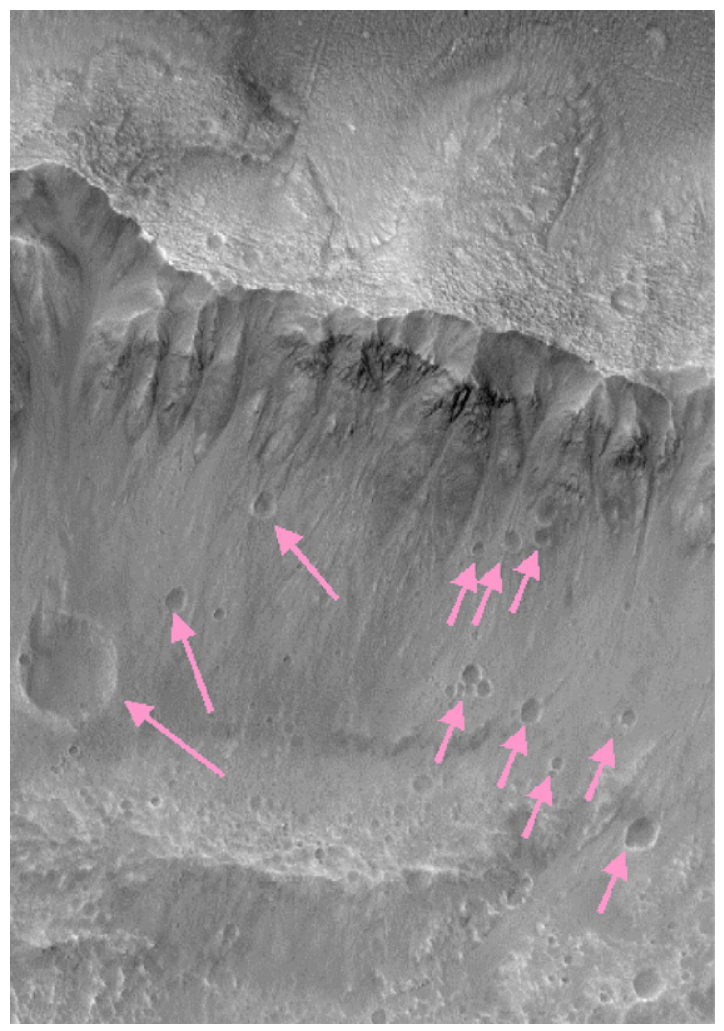

Fig. 10. Arrows point to superposed impact craters on gully systems. MOC image M2300984 (3.16 km in width) located at $39.18^{\circ} \mathrm{N}, 18.69^{\circ} \mathrm{W}$.

walls. The gully system shown in the crater of Fig. $12 \mathrm{~b}$ is particularly interesting because this poleward facing crater wall has an interesting feature comprised of a raised slab of material flowing downslope in a lobate form with compressional cracks.

In the northern hemisphere, $15 \%$ (21 MOC images) of the gully systems exhibit lobate debris apron morphologies (also described as arcuate ridges by Berman et al., 2005). These de-

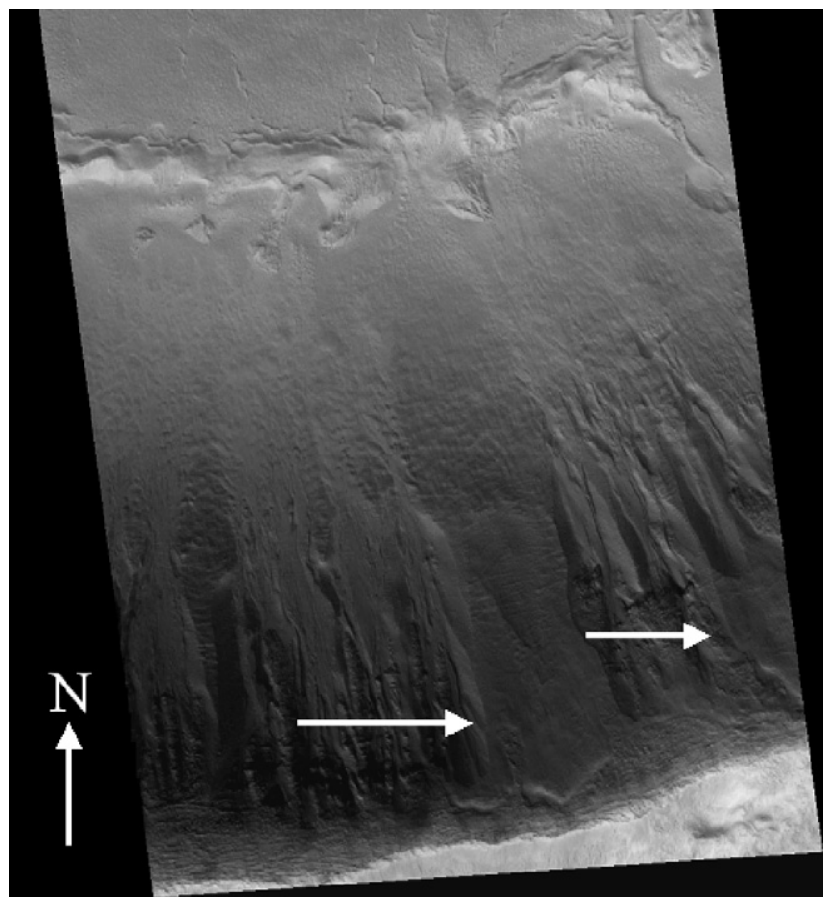

Fig. 11. Arrows point to pasted-on material on gully systems. MOC image E1400478 (3.33 km in width) located at $39.93^{\circ} \mathrm{N}, 254.86^{\circ} \mathrm{W}$.

bris aprons have crescent-shaped terminal ridges with relatively rounded, lobate planforms. The majority of these gully systems with ridged, lobate apron structures are polefacing. Fig. 13 shows an example of the lobate morphology of the gully debris aprons.

Gullies in the northern hemisphere of Mars also often have an exceptionally eroded and degraded appearance. Many of the gullies lack sharp, crisp morphologies reminiscent of other classic examples of martian gullies. The topography appears muted and in some cases the gullies appear to be overlain by a layer of dust and/or sediment. Fig. 14 shows several examples of degraded gully morphologies. Fig. 14a shows evidence of eroded alcoves that may have once had a more pristine and defined morphology. Fig. 14b shows what may have been alcoves and channels that are now infilled with another material. Fig. 14c shows evidence of both degraded and sharp gullies within the same crater at different locations on the crater wall. The gullies on the northernmost wall face appear muted and degraded in appearance. In contrast, the gullies on the southernmost wall appear sharper and clearer with more well-defined incised channel structures.

\section{Discussion}

The data based on the MGS observations as described in Section 3 may be useful for determining the formation processes of these enigmatic gully features. We now discuss possible implications of these MGS observations of the northern hemisphere gullies and then compare and contrast these observations with those documented for gullies in the southern hemisphere. 


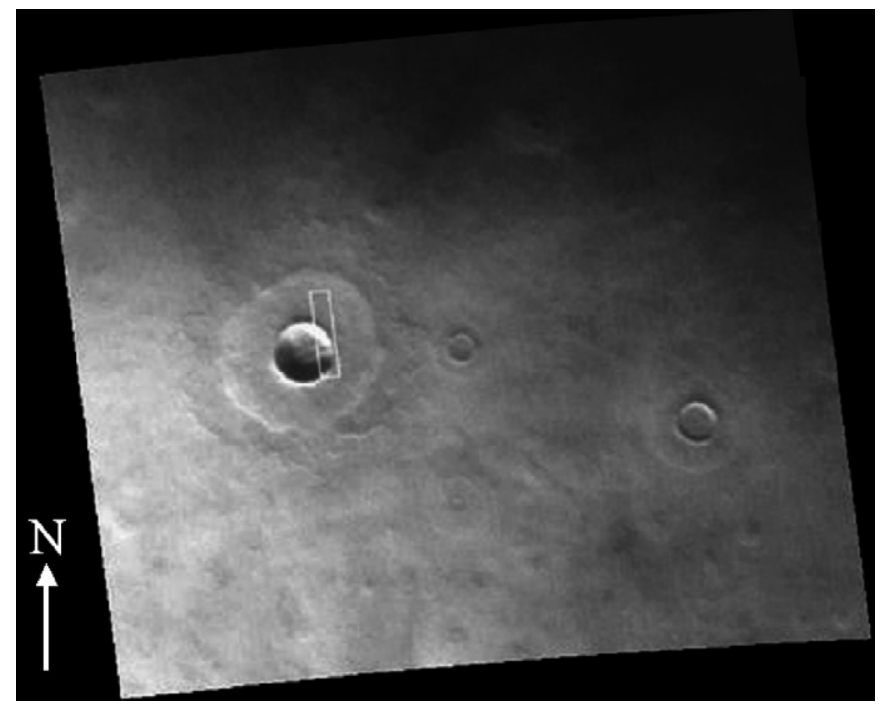

(a)

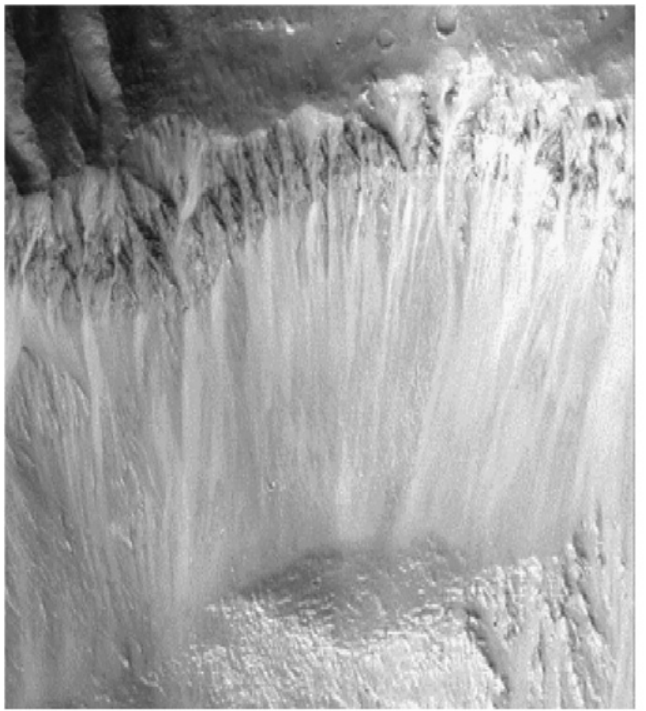

Equator facing

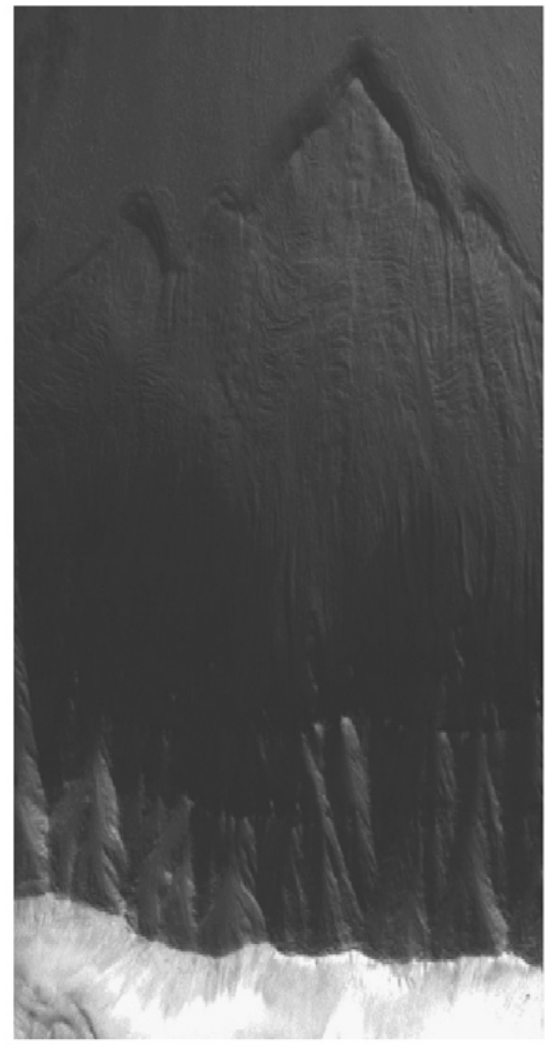

\section{Pole facing}

(b)

Fig. 12. Fig. 12a is a MOC wide-angle image showing a rampart crater harboring gullies. The white box indicates the location of the MOC narrow-angle image. Fig. $12 \mathrm{~b}$ shows an ice tongue on the poleward facing slope on the walls of a rampart crater. Note no ice tongues are visible on the equatorward facing slope. Fig. 12a is MOC image R1104040 (136.23 km in width) located at $57.33^{\circ} \mathrm{N}, 263.69^{\circ} \mathrm{W}$, Fig. 12b is MOC image R1102183 (3.30 km in width) located at $33.61^{\circ} \mathrm{N}$, $241.75^{\circ} \mathrm{W}$.

\subsection{Northern hemisphere gullies}

Gullies in the northern hemisphere of Mars have formed over a wide range of absolute elevations $(+0.8 \mathrm{~km}$ to $-5.4 \mathrm{~km})$ as shown in Fig. 4. The fact that gullies are found at such extreme ranges in elevation suggests that gullies can form regardless of present conditions of stability with respect to boiling. Haberle et al. (2001) used a general circulation model to determine the current locations on Mars where liquid water is presently stable with respect to boiling, i.e., where the ambient $\mathrm{CO}_{2}$ pressure is 


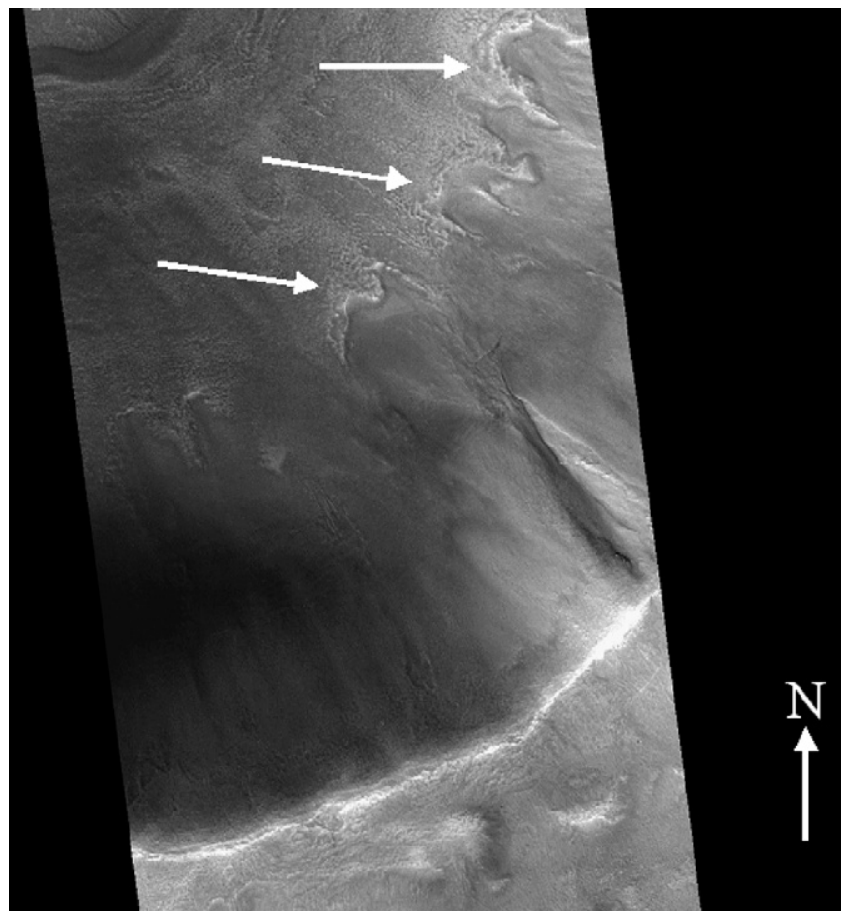

Fig. 13. Arrows point to lobate debris aprons. MOC image M1500907 $(3.09 \mathrm{~km}$ in width) located at $43.87^{\circ} \mathrm{N}, 25.60^{\circ} \mathrm{W}$.

greater than the water vapor pressure at the local temperature. In the northern hemisphere, liquid water could be stable with respect to boiling between $0^{\circ}-30^{\circ} \mathrm{N}$ in the plains of Amazonis, Arabia, and Elysium (Haberle et al., 2001). Gullies are not found equatorward of $30^{\circ} \mathrm{N}$ and are clustered in Arcadia Planitia, Tempe Terra, Acidalia Planitia, and Utopia Planitia, none of which are regions of water stability as outlined by Haberle et al. (2001). However, liquid water could persist transiently, while boiling, if emplaced on the surface at higher elevations (Hecht, 2002). The formation of the gullies has been shown to be consistent with the action of liquid water simultaneously boiling and freezing under current martian conditions (Heldmann et al., 2005b) and thus, in light of these results, it is not surprising that the gullies form in regions of water instability. Most of the northern hemisphere gullies form at elevations below the $0 \mathrm{~m}$ datum and surface pressures are greater than $6.1 \mathrm{mbar}$, the triple point of water. If gullies can only form when the water is simultaneously evaporating and freezing (Heldmann et al., $2005 b)$ then this may suggest that the northern hemisphere gullies formed in a different epoch when surface pressures may have been lower in these low elevation plains. In any case, the gullies are able to form at locations independent of absolute elevation.

The gully alcoves may be indicative of a source region of any erosive fluid which ultimately carves the gully features. The depths to the alcove bases may be representative of subsurface depths where the eroding fluid might be sequestered before being released onto the martian surface. The fluid may be released at the alcove base with subsequent headward erosion forming the alcove or may originate from a broader zone in the middle or top of the alcove and cause alcove erosion both above and below the location where the fluid is introduced onto the surface.
Based on observations of MOC images, we find that the alcoves typically commence within the upper reaches of the slope face. Assuming an erosive fluid originates within the alcove then this fluid must correspondingly originate towards the top of the slope. Models of gully formation that would be expected to operate at any location along the full length of the slope are therefore inconsistent with this observation.

Erosion forming the alcoves and channels occurs once the eroding fluid reaches the martian surface. The length of the alcoves and channels are shown in Fig. 5. Channel length is representative of the distance the fluid has traveled across the martian surface while alcove length may be representative of the amount of headward erosion carving the alcove from the host rock. Channel and alcove lengths show no systematic trends with respect to latitude. The inferred mean surface temperatures (Mellon et al., 2000) for the gully locations over this latitude range span from 179 to $219 \mathrm{~K}$ in the northern hemisphere. This may indicate that the degree of gully activity is independent of latitude (and the corresponding mean surface temperature gradient) since no obvious changes in gully size are observed as a function of latitude.

The range in alcove and channel lengths, however, may be attributed to several processes. First, shorter gullies may form in shorter timespans than longer gullies, resulting in less time for the liquid water to flow across the martian surface and carve the gully features. Sustained flow may be able to travel further on the martian surface and create longer gullies. Water released later in time may be able to take advantage of an already-carved channel structure which allows water to flow relatively unimpeded down the length of the channel. The water would then slow only towards the channel base where the channel length is extended by additional erosion. Second, shorter gullies may simply form from less water than the longer gullies. Increased flow rates can result in longer channels as more liquid water is available to carve the features before rapidly evaporating and freezing on the martian surface (Heldmann et al., 2005b).

As shown in Fig. 6, longer channels are usually associated with longer alcoves. Assuming that longer alcove lengths are formed via increased headward erosion, longer alcoves may be formed due to an increased amount of fluid emanating from the alcove and/or higher fluid exit velocities. Channel lengths, however, are typically longer than the alcove lengths by a factor of 1.76 .

Most of the slopes containing the alcoves in the northern hemisphere fall outside of the range in angle of repose (Fig. 9). Although smaller regions within the alcove appear to exhibit higher slope angles, these may form from subsequent mass wasting and headward erosion within the alcove caused by an undermining of the slope surface. These slope angles suggest the formation of the gully alcoves is probably not initiated solely by a dry downslope movement of unconsolidated soil for the majority of the gullies.

Gullies exhibit a complex latitudinal trend in orientation, including varying east-west components and north-south concentrations (see Fig. 7). The majority of gullies in the northern hemisphere are observed on equatorward facing slopes. However, since gullies are found on such a range of slope orienta- 


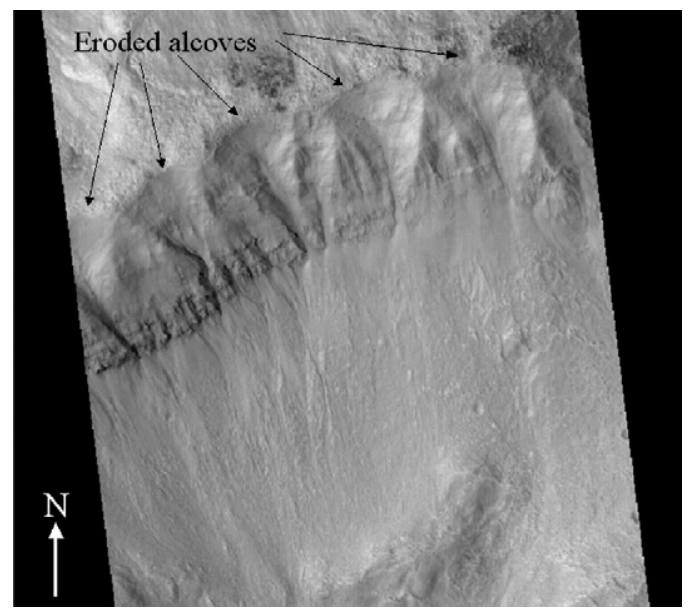

(a)

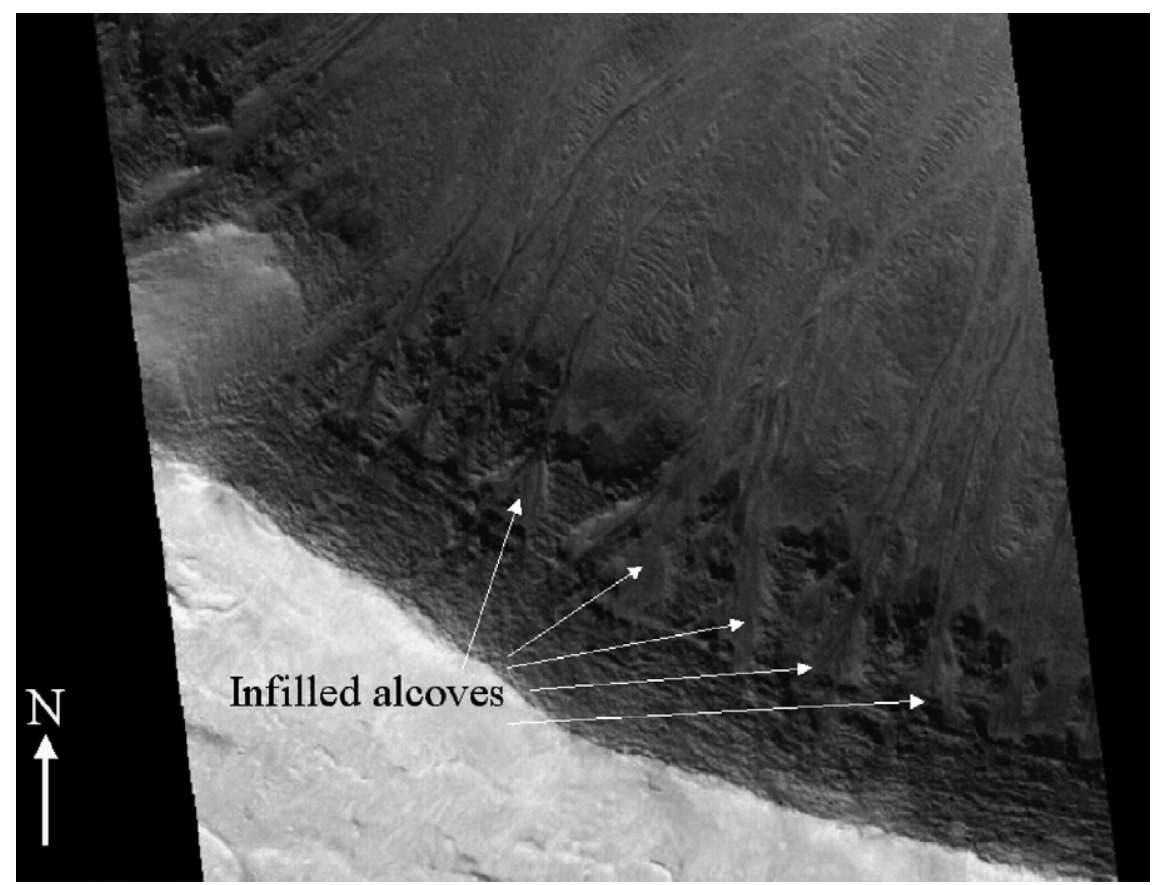

(b)

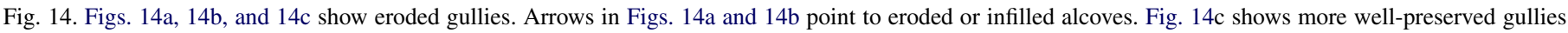

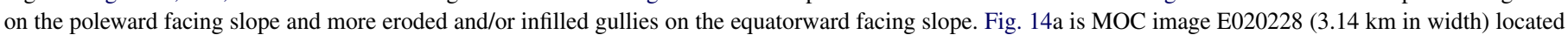

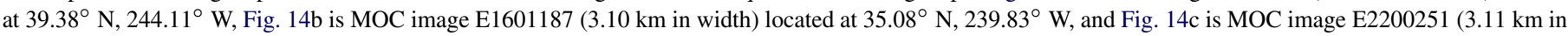
width) located at $39.08^{\circ} \mathrm{N}, 18.54^{\circ} \mathrm{W}$.

tions at all latitudes, models of gully formation must be consistent with both poleward and equatorward facing processes and characteristics, as well as all orientations in between.

There are several geomorphic features associated with the gullies which suggest a connection with the presence of past and/or recent water. First, the pasted-on material (Fig. 11) associated with the gullies may be evidence of recent snow and/or ice. Christensen (2003) suggests that the pasted-on material is the remnant of snowpacks deposited from during periods of high obliquity which subsequently melt to form the gullies. Alternatively, the pasted-on material may be a remnant ice deposit resulting from the freeze-up of the gullies as the liquid water flows on the martian surface. In either case, the pasted-on ma- terial may represent a connection with the presence of water in association with the gullies.

Second, the presence of patterned ground within and around craters harboring gullies may suggest water ice and/or melt is or was present in these locales. Patterned ground is commonly observed in the polar regions on Earth and forms via the thermally derived stresses of subsurface ice and/or sand wedges which can be manifested as ice and/or sand wedge polygons (Ritter et al., 1978). Thermal contraction cracking typically occurs in frozen, ice-rich materials with a high internal cohesive strength and generally produces polygonal patterns on the surface as the cracks intersect one another (Yoshikawa, 2000). As tensile stresses exceed tensile strengths, fractures form in the ice-rich soils. These fractures can later be filled with (1) melt- 


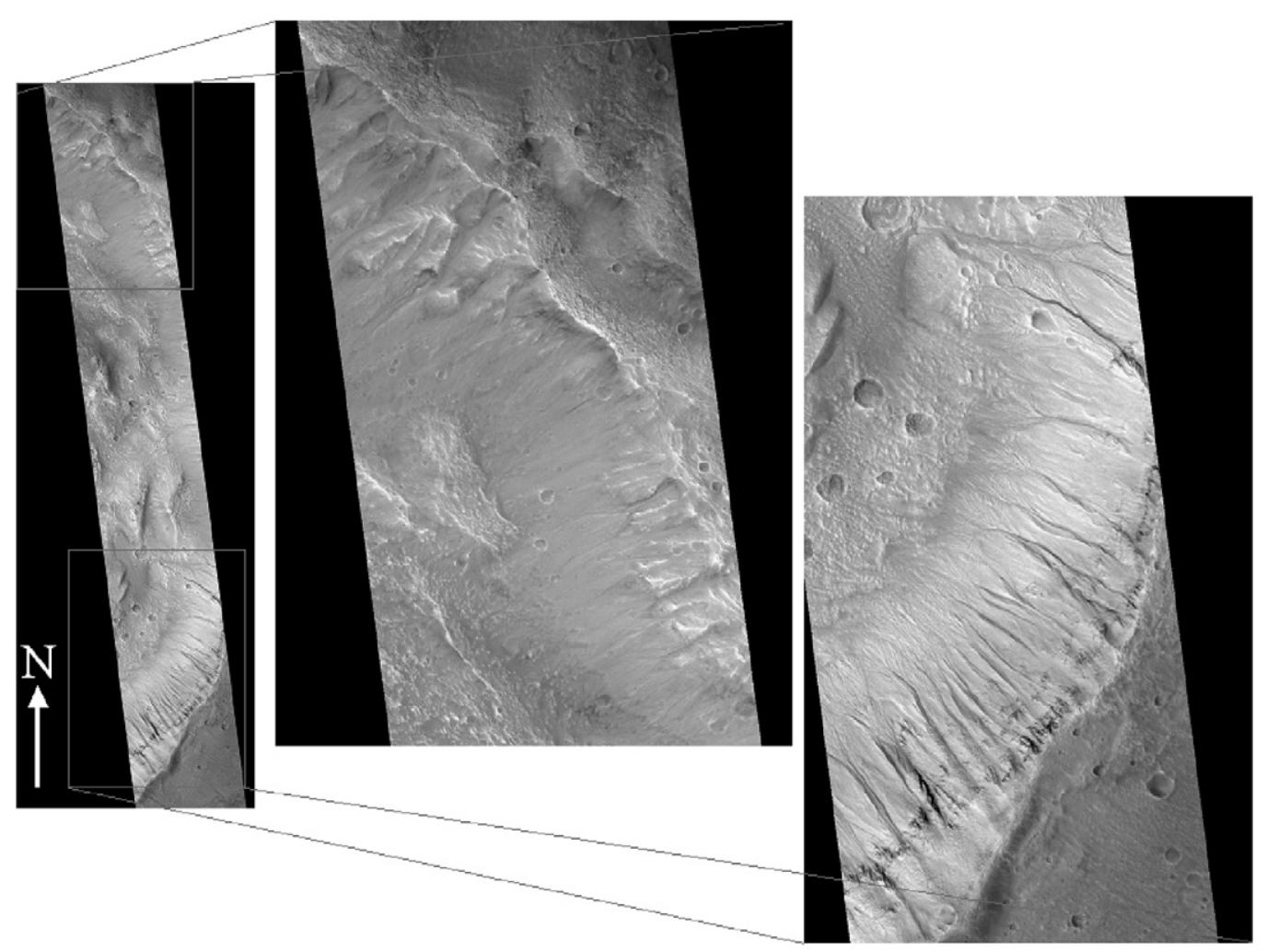

(c)

Fig. 14. (continued)

water to create ice wedges or (2) sand and other surface materials to create sand wedges (although water is still required for sand wedge formation). Modeling suggests such processes are expected on Mars (Mellon, 1997) and hence the formation of thermal contraction polygons (10-100 m diameter) is expected. Since polygons have been observed within a crater which exhibits gullies on its crater walls, this region may have been dominated by ice-rich soils. However, polygons are rare in association with gullies since most craters containing gullies do not show polygonal ground, perhaps suggesting gullies do not preferentially form in ice-rich regions.

Third, rampart craters are also suggestive of subsurface ice on Mars. Rampart craters form by surface flowage as ejecta surges lose fluidizing vapors and transported particles are deposited en masse (Wohletz and Sheridan, 1983). Such craters may form as a result of impact melting of ground ice (Carr et al., 1977) and thus may suggest that gullies forming on rampart crater walls may have formed in regions where ground ice is or once was present. However, rampart craters are relatively rare in association with gullies since most craters containing gullies do not show such lobate ejecta deposits, perhaps suggesting gullies do not preferentially form in ice-rich regions.

Fourth, lobate debris apron morphologies associated with martian gullies may also indicate the presence of near-surface water ice on Mars. These lobate ridge features are reminiscent of terrestrial rock glaciers (Hartmann et al., 2003; Howard, 2003). These aprons may have formed from sublimation of gullied fans and from massive ice (Howard, 2003). Alternatively, the lobate apron morphologies may form from a perched ice lens created from water stored in a subsurface aquifer which freezes before reaching the martian surface to flow and form the gully (Hartmann et al., 2003). Regardless of the precise origin, such structures likely result from the presence of water and/or ice. However, the lobate debris aprons are relatively rare in association with gullies, perhaps suggesting gullies do not preferentially form in ice-rich regions.

\subsection{Comparison of north and south hemisphere gully data}

Gullies on Mars show more similarities than differences between the northern and southern hemispheres. For example, gullies in both hemispheres show regional clustering. Gullies in the south are most abundant in Dao Vallis, chaotic terrain north of Terra Sirenum, and the south polar pits (Heldmann and Mellon, 2004; Balme et al., 2006). Gullies in the northern hemisphere are clustered in Arcadia Planitia, Tempe Terra, Acidalia Planitia, and Utopia Planitia. With respect to latitudinal trends, the gully population in both hemispheres tends to taper off approaching $60^{\circ}$. In the south a spike in gully occurrence is seen at $72^{\circ} \mathrm{S}$ which coincides with the south polar pits. A similar spike is not seen in the northern hemisphere which is perhaps not surprising since no analogous polar pits exist in the north. Gullies in both hemispheres show association with layering, though, as competent strata layers are observed in the majority of the gully alcoves in both the north and the south. Gullies in both hemispheres also show similar overall morphologies with continuous alcove, channel, and debris apron structures. 
Gullies in both the northern and southern hemispheres of Mars exhibit several similar aspects of morphology. For example, gullies in both hemispheres are characterized by the characteristic alcove, channel, and debris apron structures. Gullies in both hemispheres have been observed with pasted-on terrain (Christensen, 2003; Heldmann and Mellon, 2004). Gullies in both hemispheres have likewise been observed with lobate and/or arcuate debris aprons (Berman et al., 2005).

The gullies form at a wide range of elevations. Considering the locations of gullies in both hemispheres, gullies are found at a total range of elevations from approximately $-5000 \mathrm{~m}$ to $+3000 \mathrm{~m}$. The majority of this elevation range is attributed to the southern hemisphere gullies since the range of available terrains is less in the northern highlands (see Fig. 4). As previously mentioned, gullies in the north are not found in regions where water is expected to be stable with respect to temperature and pressure, e.g., Amazonis, Arabia, and Elysium (Haberle et al., 2001). In the southern hemisphere, liquid water would only be stable with respect to boiling in the Hellas and Argyre basins (Haberle et al., 2001). However, gullies are not found in these locations (Heldmann and Mellon, 2004) and so gullies in both the northern and southern hemispheres of Mars do not form in regions of water stability.

Channel and alcove lengths do not show strong trends with respect to latitude in either hemisphere. No strong trend is observed for the northern hemisphere gullies (Fig. 5). This finding is somewhat consistent with the findings based on data in the southern hemisphere. Alcove and channel lengths of gullies in the south only showed a latitudinal trend of shorter gullies at higher latitudes due to the presence of many small gullies in the south polar pits ( $72^{\circ} \mathrm{S}$ ) (Heldmann and Mellon, 2004). Removal of these high-latitude gullies from the dataset results in no latitudinal trend between $30^{\circ}-70^{\circ} \mathrm{S}$. The south polar pit data may be a product of geographical biasing and so overall, alcoves and channels exhibit similar lengths at various latitudes on Mars.

The formation of gullies does not seem to be controlled by local surface temperatures in either hemisphere. Inferred mean surface temperatures (Mellon et al., 2000) range from $218 \mathrm{~K}$ at the lower latitude to $190 \mathrm{~K}$ at the higher latitudes in the southern hemisphere (Heldmann and Mellon, 2004) compared with a range of 179 to $219 \mathrm{~K}$ in the northern hemisphere.

Longer alcoves are generally associated with longer channels in both hemispheres. Alcove and channel lengths in the southern hemisphere more closely showed a 1:1 ratio (Heldmann and Mellon, 2004) compared with a 1:1.76 ratio for the northern hemisphere. There is no particular reason to expect a 1:1 alcove:channel ratio but our findings may indicate that the gullies in the northern hemisphere are forming in a substrate more resistant to headward erosion. Alternatively the northern hemisphere alcoves may be more degraded than the southern hemisphere counterparts and so we are measuring only the remnants of once-longer alcoves. However, such degradation would be expected to affect the channels as well and assuming the channels and alcoves are degraded similarly then our current measurements would retain the same alcove:channel length ratios. Nonetheless, in both the north and the south, longer al- coves are generally correlated with longer channels. This is consistent with increased water activity carving these longer features (alcoves and channels) and decreased amounts of water activity carving the shorter features.

Most of the alcoves in the northern hemisphere fall outside of the range in angle of repose (Fig. 9) as do the majority of alcoves in the southern hemisphere (Heldmann and Mellon, 2004). Although smaller regions within the alcove appear to exhibit higher slope angles in both hemispheres, these may form from subsequent mass wasting and headward erosion within the alcove caused by an undermining of the slope surface.

Northern hemisphere gullies exhibit a complex latitudinal trend in orientation, including varying east-west components and north-south concentrations (see Fig. 7). Such variation in orientation is also seen in the southern hemisphere gullies (Heldmann and Mellon, 2004; Balme et al., 2006). A slight majority of gullies are observed on poleward facing slopes in the southern hemisphere (which may be attributed to biased MOC targeting of poleward slopes and/or image saturation of the brightly lit equatorward slopes) (Heldmann and Mellon, 2004) whereas a slight majority of gullies are observed on equatorward facing slopes in the northern hemisphere. Due to these variations in orientation, any proposed mechanism of gully formation must be consistent with both poleward and equatorward facing gullies.

The gullies in the northern hemisphere may be older than their southern hemisphere counterparts based on observations in the north of (1) high degrees of gully degradation and (2) superposed impact craters on gully systems. The exceptionally eroded and degraded appearance of many of the northern hemisphere gullies (see Fig. 14) suggests that either (1) these gullies are relatively old and have had time to be eroded or else that (2) the northern hemisphere gullies are simply subject to higher erosion rates than the southern hemisphere gullies and both sets of gullies are of the same age. The presence of superposed impact craters on northern hemisphere gully systems (see Fig. 10) is also suggestive of a relatively older age for the northern hemisphere gullies. Alternatively, these gullies may be of the same age as the southern hemisphere gullies but may have formed in areas of unusually high impact rates.

\section{Constraint on proposed models}

In this section we review several proposed hypotheses of gully formation and the potential source of an erosive material. We examine these hypotheses for predicted characteristics that can be used to constrain these models including (1) morphology, (2) subsurface temperature regime, (3) latitudinal distribution, (4) orientation, (5) alcove depth, and (6) slope angle, taking into account the data pertaining to both the northern and southern hemisphere gullies.

\subsection{Liquid carbon dioxide reservoir}

Liquid carbon dioxide has been proposed as the main agent of erosion in the formation of the gullies where a liquid $\mathrm{CO}_{2}$ reservoir forms in the martian subsurface behind the exposed 
slope housing the gullies and below the upslope plateau as shown in Fig. 1 and detailed in Musselwhite et al. (2001).

There are several difficulties that arise from the $\mathrm{CO}_{2}$ model that were discussed by Heldmann and Mellon (2004) and still remain unresolved. These issues are more thoroughly explained in Heldmann and Mellon (2004) and are only summarized here. For example, $\mathrm{CO}_{2}$ cannot condense from the atmosphere into the subsurface because of unfavorable surface and subsurface temperature regimes. Carbon dioxide would be unstable in the martian subsurface over geologic timescales (Stewart and Nimmo, 2002). Likewise, an adequate supply of $\mathrm{CO}_{2}$ to supply the subsurface has yet to be found (Stewart and Nimmo, 2002).

\subsubsection{Morphology}

Gully morphology is also inconsistent with a carbon dioxide formation process. The exit velocity of the $\mathrm{CO}_{2}$ is expected to be on the order of $100 \mathrm{~m} / \mathrm{s}$ (Stewart and Nimmo, 2002). The morphology of the martian gullies in both the northern and southern hemispheres (i.e., sinuous channels and the deflection of channel paths around low topographic features) implies lower flow velocities. Plus, carbon-dioxide ladened debris would travel through the atmosphere approximately $100 \mathrm{~m}$ after being ejected from the subsurface (Stewart and Nimmo, 2002), but both the northern and southern hemisphere martian alcoves and channels are not discontinuous and show no evidence of such large eruptions.

\subsubsection{Latitudinal distribution}

The carbon dioxide model also does not explain the geographical distribution of gullies. The dearth of gullies between $30^{\circ} \mathrm{N}$ and $30^{\circ} \mathrm{S}$ (Malin and Edgett, 2000; Edgett et al., 2003) still remains unresolved. Also, the general latitudinal distribution shown in Fig. 3 also remains unexplained. Gullies follow a similar latitudinal trend in both the northern and southern hemispheres (most gullies are located at more equatorward latitudes $\left(30^{\circ}-45^{\circ}\right)$ with the concentration of gullies decreasing with increasing latitude up to $\sim 72^{\circ}$ ).

\subsubsection{Orientation}

The orientation trends of the martian gullies may not be entirely inconsistent with the carbon dioxide model. Gullies in the southern hemisphere have been observed more often on poleward facing slopes (Heldmann and Mellon, 2004) while gullies in the northern hemisphere have been observed more often on equatorward facing slopes (Fig. 7; Edgett et al., 2003). The $\mathrm{CO}_{2}$ model provides no mechanism in which the reservoir would form or release liquid $\mathrm{CO}_{2}$ on a preferred slope orientation as a function of latitude if such trends are real. However, orientation may not be a driving factor in gully formation since overburden soil thermal properties may compensate for the orientation (and resultant surface thermal conditions) (Mellon and Phillips, 2001).

\subsubsection{Subsurface temperature regime}

If the gullies are formed via release from a $\mathrm{CO}_{2}$ reservoir, then this reservoir must reside within the temperature-pressure
Table 1

Subsurface temperature calculations: Model parameters

\begin{tabular}{llllll}
\hline Property & $\begin{array}{l}\text { Param- } \\
\text { eter }\end{array}$ & $\begin{array}{l}\text { Icy soil } \\
\left(\mathrm{CO}_{2} \text { ice }\right)^{\mathrm{e}}\end{array}$ & $\begin{array}{l}\text { Icy soil } \\
\left(\mathrm{H}_{2} \mathrm{O} \text { ice }\right)^{\mathrm{e}}\end{array}$ & $\begin{array}{l}\text { Dry } \\
\text { soil }\end{array}$ & Units \\
\hline Soil density & $\rho$ & $2274^{\mathrm{b}}$ & $2018^{\mathrm{d}}$ & $1650^{\mathrm{d}}$ & $\mathrm{kg} / \mathrm{m}^{3}$ \\
Heat capacity & $c$ & - & $1287^{\mathrm{d}}$ & $837^{\mathrm{d}}$ & $\mathrm{J} /(\mathrm{kg} \mathrm{K})$ \\
Thermal conductivity & $k$ & $0.5^{\mathrm{c}}$ & 2.4 & $I^{2} / \rho c$ & $\mathrm{~W} /(\mathrm{m} \mathrm{K})$ \\
Gravity & $g$ & 3.71 & 3.71 & 3.71 & $\mathrm{~m} / \mathrm{s}^{2}$ \\
Geothermal heat flux $^{\mathrm{a}}$ & $q$ & 30 & 30 & 30 & $\mathrm{~mW} / \mathrm{m}^{2}$ \\
\hline
\end{tabular}

a The martian geothermal heat flux $(q)$ has never been measured but theoretical values range from $20-45 \mathrm{~mW} / \mathrm{m}^{2}$ and so we adopt the typical value of $30 \mathrm{~mW} / \mathrm{m}^{2}$ (Johnston et al., 1974; Fanale, 1976; Toksoz and Hsui, 1978; Toksoz et al., 1978; Davies and Arvidson, 1981; Stevenson et al., 1983; Franck and Orgzall, 1987; Schubert and Spohn, 1990; Spohn, 1991). Results are not very sensitive to the value of $q$. See Mellon and Phillips (2001) for further discussion of geothermal heat values.

b Weast (1986).

c Kravchenko and Krupskii (1986).

d Mellon and Phillips (2001).

e Values assume ice saturation at $40 \%$ porosity.

stability field of liquid $\mathrm{CO}_{2}$. To examine the potential presence of a liquid $\mathrm{CO}_{2}$ reservoir at the observed alcove depths we compare estimates of subsurface pressure and temperature with the phase stability regime of carbon dioxide. Here we calculate the pressure-temperature regimes of 41 individual alcove bases from 10 different MOC image scenes containing gullies. (We are limited to performing these calculations on these 41 alcove bases because accurate coalignment of the MOC and MOLA data requires a simultaneous MOLA track taken with each MOC image. Most MOC gully images in the northern hemisphere were taken later during the MGS mission, after the MOLA instrument ceased collecting data.)

Following the methodology of Heldmann and Mellon (2004), we use the measured TES thermal inertia $(I)$ at each gully site as well as modeled mean surface temperatures $\left(T_{0}\right)$ (Mellon et al., 2000) to compute the subsurface temperature at the depth of each individual alcove base. For a given alcove base depth $(z)$ the lithostatic pressure of a subsurface aquifer is calculated as $P=\rho g z$ and the aquifer temperature is calculated from conduction of geothermal heat as $T=(q / k) z+T_{0}$ using values for gravitational acceleration $(g)$, geothermal heat flux $(q)$, and thermal conductivity $(k)$ from Table 1 . We assume a constant thermal conductivity through the soil column and determine the subsurface thermal regime for a dry overburden and an icy $\mathrm{CO}_{2}$ overburden to consider a wide range of possibilities with respect to the overlying soil type. For the dry overburden case we compute the thermal conductivity based on the TES thermal inertia at each location since thermal inertia $(I)$, thermal conductivity $(k)$, density $(\rho)$, and specific heat $(c)$ are related by $I=$ $\sqrt{k \rho c}$. Because the thermal inertia only characterizes the thermal properties of the upper few centimeters of the soil surface, we recognize that the resulting thermal conductivity may not be representative of the conductivity of the entire soil column and so we also consider different plausible conductivity values.

Depth and subsurface temperature of gully alcove bases are compared with the $\mathrm{CO}_{2}$ phase space for both the dry and icy overburden cases. Assuming a dry overburden soil with model parameters as listed in Table 1, all of the gully alcove bases 
fall within the gaseous $\mathrm{CO}_{2}$ regime. Assuming a $\mathrm{CO}_{2}$-ice laden soil overburden with model parameters as listed in Table 1, still none of the gully alcove bases fall within the temperaturepressure space of liquid $\mathrm{CO}_{2}$.

Although our initial calculations suggest that none of the gully alcoves lie within the liquid $\mathrm{CO}_{2}$ regime, we consider the possibility that the thermal conductivity of the overlying soil may be different from the values used in the previous calculations due to variations in the overburden composition. We therefore calculate the effective thermal conductivity needed to position all of the gully alcoves within the temperature-pressure regime of liquid $\mathrm{CO}_{2}$. Alcoves originally located within the solid $\mathrm{CO}_{2}$ regime require thermal conductivities ranging from 0.12 to $22.48 \mathrm{~W} /(\mathrm{m} \mathrm{K})$ with an average value of $3.09 \mathrm{~W} /(\mathrm{m} \mathrm{K})$ to reach subsurface temperatures equaling the $\mathrm{CO}_{2}$ triple point temperature. It is therefore theoretically possible to increase the calculated temperatures at the measured depth of the alcove bases by generally assuming a drier overburden (lower thermal conductivity) such that these values are above the triple point temperature of $\mathrm{CO}_{2}$. However, the pressure at these depths is still too low to move the alcove bases into the liquid $\mathrm{CO}_{2}$ regime. Increased overburden ice content can increase the overburden pressure at depth but this is inconsistent with the temperature analysis since increasing the temperature at depth requires a drier overburden with less ice content. It is therefore not possible for all of the gully alcove bases to reside within the liquid $\mathrm{CO}_{2}$ temperature-pressure regime; a liquid $\mathrm{CO}_{2}$ aquifer cannot exist at the observed alcove base depths for all the gullies. This finding is consistent with results for the southern hemisphere (Heldmann and Mellon, 2004).

There are several unresolved problems with the carbon dioxide gully model and these same problems exist for gullies in both the northern and southern hemispheres on Mars. Liquid $\mathrm{CO}_{2}$ cannot condense in the subsurface in sufficient quantities to form the martian gullies. The morphology of the gullies is inconsistent with a $\mathrm{CO}_{2}$ origin and the $\mathrm{CO}_{2}$ hypothesis does not explain the geographic or orientation distribution (if applicable) of the martian gullies. It is not possible given the observational constraints imposed by the MGS data for all supposed aquifers at the observed alcove base depths to reside in the liquid temperature and pressure phase space of $\mathrm{CO}_{2}$. Based on all of these reasons, we conclude that carbon dioxide is an unlikely eroding agent to carve the martian gullies.

\subsection{Shallow liquid water aquifer}

The shallow aquifer model (detailed in Mellon and Phillips, 2001) predicts several gully trends which we now test via comparisons with the observations.

\subsubsection{Latitudinal distribution}

First, gullies should be found poleward of $30^{\circ}$ where ground ice (for the icy-soil plug) is thermodynamically stable (Mellon and Phillips, 2001). This dependence on ground ice stability would explain the lack of any gullies between $30^{\circ} \mathrm{N}$ and $30^{\circ} \mathrm{S}$ (Malin and Edgett, 2000; Edgett et al., 2003). Additionally, Mellon and Phillips (2001) predict that a dearth of gullies should occur between latitudes of $\sim 60^{\circ}$ and $65^{\circ}$. As the martian obliquity varies between $20^{\circ}$ and $40^{\circ}$, the depth to the $273 \mathrm{~K}$ melting isotherm undergoes the least amount of change near $60^{\circ}$ latitude. At these latitudes a shallow aquifer would not undergo the freeze-thaw cycles necessary to build up the required pressures within the aquifer to cause the subsequent release of the aquifer water. The latitudinal distribution of gullies shown in Fig. 3 indicates that the number of gullies decreases as latitude increases up to $\sim 60^{\circ} \mathrm{N}$ and then the least amount of gullies are found poleward of $60^{\circ} \mathrm{N}$. This trend in latitudinal gully distribution with a minimum number of gullies near $60^{\circ}$ is largely consistent with the predictions of the shallow aquifer model of Mellon and Phillips (2001). A dearth of gullies was also observed in the southern hemisphere near $60^{\circ} \mathrm{S}$ (Heldmann and Mellon, 2004).

\subsubsection{Subsurface temperature regime}

Assuming that the liquid water source for the gullies is a shallow aquifer and that the alcove bases are the most likely locations of water release, then the alcove bases must be within the temperature-pressure regime of liquid water. We test this hypothesis by comparing the subsurface pressure and temperature of the alcove base depths with the water phase stability diagram. Similar to the analysis previously used to examine the potential for a $\mathrm{CO}_{2}$ liquid reservoir, we consider a liquid water reservoir buried beneath the upslope plateau at depths corresponding to the gully alcove bases in the same configuration as shown in Fig. 1. Based on the measured TES thermal inertia $(I)$ at each gully site as well as modeled surface temperatures (Mellon et al., 2000), the subsurface temperature at the depth of each observed alcove base is computed for both the water-ice laden soil and dry soil overburden cases. Assuming an icy overburden soil with model parameters as listed in Table 1, $98 \%$ of the gully alcove bases fall within the solid $\mathrm{H}_{2} \mathrm{O}$ portion of the phase diagram. An icy overburden soil results in depths to the $273 \mathrm{~K}$ isotherm ranging from 4525 to $7933 \mathrm{~m}$ which is inconsistent with the observed depths of the gully alcoves. However, assuming a dry overburden soil with parameters as listed in Table 1, only 5\% of the gully alcoves fall within the solid $\mathrm{H}_{2} \mathrm{O}$ regime while $95 \%$ of the gully alcoves fall within the liquid $\mathrm{H}_{2} \mathrm{O}$ regime. This computation assumes that the subsurface thermal conductivity is constant throughout the entire column of overburden.

If the gullies were formed via liquid water in a shallow aquifer, then the subsurface regime at the alcove base depth must lie within the stability field of liquid water. We therefore examine several different mechanisms which may effectively move the $5 \%$ of the gullies from the solid water regime to the liquid water regime. The presence of soluble salts results in a freezing point depression that can allow water on Mars to exist in the liquid state below 273 K (Brass, 1980; Knauth and Burt, 2002). The lowest calculated subsurface temperature of an alcove base is $\sim 239 \mathrm{~K}$ (assuming a dry overburden) which would require a freezing point depression of $34 \mathrm{~K}$. Such freezing point depressions are possible given a unique mixture of salts, and so this scenario remains possible (Brass, 1980). However, such a situation is geologically improbable 
given the lack of evidence of salt deposits associated with the gullies and the geologically unique set of circumstances which would have to persist over vast geographic areas to produce waters with complex salt eutectic chemistries in regions of gully formation.

Alternatively, the gully alcove bases originally placed within the solid water regime may actually lie within the temperaturepressure regime of liquid water if different values for the thermal conductivity of the overburden soil are applicable. Given that thermal conductivities can vary by orders of magnitude for different geologic materials (Farouki, 1986), the effective thermal conductivity was calculated such that each gully alcove base would have a subsurface temperature of $273 \mathrm{~K}$. The necessary thermal conductivities range from 0.04 to $0.24 \mathrm{~W} /(\mathrm{m} \mathrm{K})$ with an average value of $0.16 \mathrm{~W} /(\mathrm{m} \mathrm{K})$ which are geologically possible and plausible values consistent with a composite subsurface material composed of rock and loosely consolidated soil. In addition, these thermal conductivity values can be obtained from a higher conductivity subsurface soil with a varying amounts of low conductivity layered material; the presence of a layered subsurface is consistent with the frequent occurrence of layered strata at the gully alcove locations. Additionally, our calculated thermal conductivity values are plausible when compared with experimental values of soil conductivities under martian atmospheric pressures (Presley and Christensen, 1997). The lowest conductivity is that of fine soil and corresponds with observed martian thermal inertias (Presley and Christensen, 1997; Mellon et al., 2002). Hence it is very possible that all the gully alcove bases lie within the stability field of liquid water. Such a finding implies that liquid water could exist in an aquifer at these depths. A similar result was found for gullies in the southern hemisphere (Heldmann and Mellon, 2004).

\subsubsection{Orientation}

At lower latitudes gullies are expected to preferentially form on poleward-facing (colder) slopes to preserve the near-surface ground ice for the ground-ice plug. Closer to the poles one should expect less preference for gully orientation because ground ice is stable on all slopes. The latitudinal distribution of gully orientation angles is shown in Fig. 7. Gullies are preferentially found on equatorward facing slopes closest to the equator $\left(30^{\circ}-58^{\circ} \mathrm{N}\right)$ which is unexpected. At the more poleward latitudes $\left(58^{\circ}-72^{\circ} \mathrm{N}\right)$ the gullies are more evenly divided between equatorward and poleward facing slopes. These trends are not entirely consistent with the original predictions of Mellon and Phillips (2001) and there are two possible explanations for these apparent discrepancies: (1) the shallow aquifer model may be incorrect or (2) regional variations in the thermal properties of the soil may compensate for the deviation from original predictions of gully orientations (Mellon and Phillips, 2001).

\subsubsection{Alcove depth}

The depth to the bottom of the alcove may serve as a good proxy for determining the depth to a subsurface aquifer that is the water source because typically fluids emanate from the alcove base and cause headward erosion of the alcove struc- ture. We calculate the depth to the $273 \mathrm{~K}$ isotherm using the model parameters as listed in Table 1 along with measured values of TES thermal inertia and modeled surface temperatures for each gully location. The depth to the $273 \mathrm{~K}$ isotherm is typically within a few hundred meters which is consistent with the actual measured alcove depths reported here and in previous works (Gilmore and Phillips, 2002; Heldmann and Mellon, 2004), thereby suggesting that liquid water can exist at the observed alcove base depths. A similar result was found for gullies in the southern hemisphere (Heldmann and Mellon, 2004).

Hartmann (2001) has also suggested that a shallow aquifer may be the source of water for the martian gullies and hypothesizes that the aquifer is kept warm via localized geothermal heating which melts permafrost ice. Several studies including martian meteorite analysis (Nyquist et al., 2001) and crater density studies of lava flows (Hartmann and Berman, 2000; Hartmann and Neukum, 2001) have suggested that geothermal heating has occurred on Mars in the last 10-300 Ma and possibly more recently. Hartmann (2001) suggests that these heating events would be relatively low intensity and thus would not be manifested as surface expressions of volcanism which explains why gully sites are not associated with observations of volcanic features. Localized geothermal heating could, however, explain the clustering in the geographic distribution of the gullies since gullies would only form in the discrete locations of enhanced geothermal activity. The geothermal activity model remains as an intriguing hypothesis and perhaps warrants further exploration with observations and numerical modeling of heat convection and mantle plume behavior in the martian subsurface.

\subsection{Melting ground ice}

The melting ground ice model (Costard et al., 2002) predicts several trends that can be tested by observation. Several of these trends are also outlined in Heldmann and Mellon (2004) and are summarized here in light of the new northern hemisphere observations.

\subsubsection{Subsurface temperature regime}

If gullies form from melting ground ice then the gullies should be found where subsurface temperatures reach the melting point of water. According to Costard et al. (2002), daily mean temperatures reach $273 \mathrm{~K}$ in the mid and high latitudes above $30^{\circ}$ on poleward-facing slopes during the past obliquity cycles. Therefore gullies are expected to form in these locales. However, Mellon and Mellon and Phillips (2001) show that the maximum temperature of the ice table is more highly dependent upon the atmospheric saturation temperature than slope and the ice table does not reach the melting point. Temperatures above $273 \mathrm{~K}$ do not occur where ground ice is present because as subsurface temperatures increase, the ice sublimates away quickly and is gone before the subsurface temperature reaches 273 K. Also, Mellon and Jakosky (1995) predict that nearsurface ground ice should be present globally at high obliquities. Thus if the ice table could ever reach the melting point, then gullies should be able to form on all slopes globally, which is not observed. 
Also, near-surface ground ice should be present throughout the martian subsurface along the length of a slope and temperatures should not vary significantly along a slope surface at different elevations (Mellon and Phillips, 2001). Therefore, there should be no location along a slope face that would favor gully formation. If ground ice could melt, ground ice should melt along the entire length of a slope. However, the gully alcoves typically are found near the top of the slope, inconsistent with the melting ground ice model.

Mellon and Phillips (2001) have shown that ice will not be present in the subsurface where temperatures reach $273 \mathrm{~K}$. As temperatures rise, ice quickly sublimates away such that the depth of the $273 \mathrm{~K}$ isotherm is always above the depth of the near-surface ground ice. Temperatures are only high enough at high obliquities to melt the ice if the ice is composed of $15-40 \%$ salts. Such high salt concentrations could leave high albedo deposits near the gullies, though such features have not yet been observed.

Gilmore and Phillips (2002) have expanded upon the ground ice hypothesis and suggest that the exposed layers of cohesive strata associated with the gully alcoves act as an aquiclude. In this model, ground ice melts and trickles down into the subsurface until the meltwater encounters an impermeable rock layer. The water then flows along this impermeable layer until it reaches the martian surface and flows down a cliff face to create a gully. In this scenario, the water should flow along the first rock layer it encounters. However, gully alcoves are often found embedded within numerous rock strata layers. Assuming each of these morphologically indistinct rock layers have similar permeabilities, it is difficult to reconcile why the gullies would not be primarily associated with the uppermost rock layer, which would be the first layer that the trickling water would encounter. Also, since the ground ice would first melt near the surface, it will be difficult for this water to trickle down through unmelted ground ice and the colder subsurface soil to reach the underlying impermeable rock layer without first refreezing. Although we maintain that a genetic relationship between the gullies and the exposed rock layers does exist, the rock layers are probably not acting as an aquiclude as suggested by Gilmore and Phillips (2002).

\subsection{Dry landslide}

Treiman (2003) suggests that the gullies were formed from the downslope movement of fine granular material in the form of dry landslides. The morphology, spatial distribution, orientation, and slope angles of expected dry landslides are now compared with observations to test this hypothesis. Several of these lines of reasoning are also outlined in Heldmann and Mellon (2004) and are summarized here in light of the new northern hemisphere observations.

\subsubsection{Morphology}

First, dry landslides exhibit several morphologic properties inconsistent with the martian gully systems. The martian gullies have sinuous, incised, V-shaped channels that often follow the local topography. The morphology of dust avalanches or dry landslides is typically narrow, fan-shaped dark streaks which gradually taper and run down a slope in a linear fashion (Sullivan et al., 2001). These slope streak features lack welldeveloped alcoves, sinuous or incised channels, and broadened triangular-shaped depositional aprons with noticeable topographic relief. Such features are very distinct from gully morphology. Snow avalanches are sometimes used as a terrestrial analog for dry debris flows, and in these cases eroded alcoves can form but as conceded by Treiman (2003), "no dry snow avalanches ... show the deep entrenched meanders of the martian gullies." Dry landslides also do not explain the incision of gully channels into the host rock; any channel-type feature formed by such mass wasting is due to the deposition of avalanching material instead of erosion of the pre-existing, underlying rock. Hence, the martian gullies are geomorphically inconsistent with a dry landslide origin.

\subsubsection{Slope angle}

Second, if the gullies have formed via mass wasting processes then the slope angle of the source region should be greater than the angle of repose. This angle typically ranges between $26^{\circ}-35^{\circ}$ depending on the climate and the lithology of the material (Ritter et al., 1978). The angle of the broad slope encompassing the gully alcove has been determined using the alcove length as well as the alcove head and base elevations. Fig. 9 shows that most alcoves are found on slope angles that are less than the angle of repose. Fifty-five percent of alcove slope values are outside of the range of repose angles and of the values outside of this range, most (83\%) are less than the angle of repose. Therefore mass wasting is most likely not the dominant mechanism acting to form the gully alcoves. Post-gully modification by mass wasting could occur on steeper slopes within the alcoves once they have already formed but the main cause of alcove formation is not due to mass-wasting.

\subsubsection{Latitudinal distribution and orientation}

Additionally, the dry mass wasting theory has difficulty accounting for the geographic distribution (Fig. 2) and the potential slope orientation trends (Fig. 7) of the martian gullies. According to this hypothesis, gullies should be most abundant east of Tempe Terra and in western Chryse because this is where the winds decelerate significantly and hence eolian sediment will be deposited and accumulate in these regions (Treiman, 2003). As shown in Fig. 2, gullies are found within Tempe Terra and more abundantly in nearby Acidalia Planitia, but are also found in Utopia Planitia and Arcadia Planitia in significant numbers which is not predicted by the dry landslide model. The landslide hypothesis also predicts that gullies will preferentially be found on poleward facing slopes in the southern hemisphere because according to the GCM, winds mostly blow into the southern hemisphere from the north-north-west and hence most sediment deposition will occur on the lee sides of slopes, i.e., pole-facing slopes. In the northern hemisphere, Treiman (2003) predicts that the orientation of the gullies will be more irregular since the wind patterns in the north are much less consistent than in the south. The martian gullies show a complex pattern with respect to orientation as shown in Fig. 7 with an overall 
preference for equator-facing slopes. This equator-facing preference is most pronounced between $44^{\circ}-58^{\circ} \mathrm{N}$ but is evident at other latitude bands as well. A connection between wind direction and gully orientation is unclear and further work may help to elucidate this issue.

The observations of spatial extent and localized trends in gully occurrence are difficult to reconcile by correlating wind behavior with gully formation. Gully systems are composed of multiple gully alcove-channel-debris apron structures and often can be observed at the scale of MOC narrow angle images. The gully systems sometimes only span a small fraction of the horizontal length of a cliff face and if gully formation were dependent on the large-scale atmospheric process of wind deceleration and subsequent sediment deposition, one might expect the gully features to be much larger in extent and/or not limited to a relatively small portion of a given slope. Plus, it is difficult to explain why gullies are sometimes found on one scarp face and not on an adjacent scarp which should theoretically be exposed to a similar wind regime. Similarly, if gully locations are tied to preferred wind directions then gullies should not form on all orientations of a given crater unless wind directions changed drastically over time. However, gullies can be found on all sides of the walls of some craters and appear to be contemporaneous; therefore it is difficult to explain this observation by invoking changing wind directions over time. There is also no reason to expect the observed regularity in the alcove depth distribution and so again the dry landslide idea does not explain the observed characteristics of the gullies.

However, a potential correlation between gully occurrence and locations of sediment deposition based on GCM wind models is still interesting even if the gullies are not formed via mass wasting. As pointed out by Heldmann and Mellon (2004), the shallow aquifer model of Mellon and Phillips (2001) requires a low thermal conductivity overburden layer (i.e., significant quantities of loosely consolidated material overlying the subsurface aquifer) in order to have a liquid water aquifer at several hundred meters depth. The deposition of fine grained material in regions of gully formation may provide a mechanism for preferentially providing this insulating overburden layer in many areas where gullies are found.

\subsection{Snowmelt}

Christensen (2003) has proposed that the martian gullies are formed by snowmelt. As discussed in Heldmann and Mellon (2004), the snowmelt model predicts several trends which can be tested by observation.

\subsubsection{Orientation}

First, the orientation of the gullies should show a distinct preference for poleward-facing slopes in the snowmelt model since these slopes are the coldest regions for ice and snow accumulation at all latitudes at current and higher obliquities (Mellon and Phillips, 2001). Similar to the theory of Bridges and Hecht (2002) and Hecht (2002), local coldtrapping in these preferred (pole-facing) locations of water ice, frost, and snow may allow for accumulation which can then melt under ideal conditions. However, as shown in Fig. 7, gullies form on all slope orientations and most gullies face equatorward in the northern hemisphere. One might also expect the gullies to follow the cold traps for snow deposition such that the gullies would be preferentially located on poleward facing slopes closer to the equator (where temperatures are generally colder) and then this slope preference would gradually dissipate since closer to the pole, all slopes are generally colder. However, Fig. 7 shows that this is not the case and instead the gullies show a complex orientation distribution with respect to latitude.

\subsubsection{Alcove base depth}

The snowmelt model also still does not explain the observed locations of the gullies along the slopes as pointed out previously by Heldmann and Mellon (2004). Gullies generally form near the top of the encompassing slope and individual gullies within a gully system begin at the same depth below the overlying plateau. However, insolation which provides heat for melting is relatively evenly distributed along a slope and so one would expect melting to occur at any location of snow accumulation. Therefore gullies would be expected to form all along a given slope which is not observed. Additionally, gully alcove base depths range from 100 to $550 \mathrm{~m}$ with an average depth of $350 \mathrm{~m}$ in the northern hemisphere. Most gullies follow this trend of alcoves depths of a few hundred meters and the snowmelt model does not account for this observation.

\subsubsection{Latitudinal distribution}

Also as pointed out by Heldmann and Mellon (2004), if the gullies have a snowmelt origin then one might expect a relatively homogeneous geographic distribution of gullies. This model is dependent upon the widespread phenomenon of snowfall and it is unclear why gullies would be so clustered in terms of location (see Fig. 2). Additionally, gullies are often found where adjacent scarps and cliffs lack gullies. If gully formation is dependent upon snowfall then it is puzzling why gullies would be found in one location and not another nearby location if both regions are subjected to similar atmospheric conditions and hence snowfall. These inconsistencies between prediction and the geographic distribution of the gullies are problematic for the snowmelt hypothesis.

\subsubsection{Morphology}

The identification of potential remnants of the original snowpacks that are protected from sublimation by a layer of desiccated dust has been an important component in the snowmelt hypothesis. This "pasted-on" material (or occupied alcoves as classified by Malin and Edgett, 2000) is cited as observational evidence for these remnant snowpacks (Christensen, 2003). However, the pasted-on material is present only rarely and one might expect a bigger abundance of occupied alcoves if snow is a dominant source of water for the gullies. There are several alternate possibilities to explain the origin of this pasted-on material. These deposits could be (1) isolated events not associated with gully formation, (2) ice of subsurface origin, or (3) remnant ice deposits formed from the freeze-back of water that flowed through the gully channels. 


\subsubsection{Temperature regime}

Another major issue for the snowmelt hypothesis comes from the results of numerical modeling of snowpacks on Mars. Clow (1987) showed that to get significant runoff from a melting snowpack requires a 100 mbar atmosphere. Also, as the snowpack becomes too thick ( $\sim 35 \mathrm{~cm}$ for this Mars case), meltwater (which is generated at the top of the snowpack) refreezes before reaching the base due to the cold conditions of the lower snowpack. This finding highlights the important distinction between meltwater and runoff (Clow, 1987). It is runoff that is needed to carve the gullies into the underlying host rock; the generation of meltwater is not enough.

Kossacki and Markiewicz (2004) likewise suggest that snow cannot melt in sufficient quantities to create the gullies on current Mars. They find a typical melt rate generating only $0.2 \mathrm{~kg} / \mathrm{m}^{2}$ of liquid. Their overall conclusion is that the predicted amount of moisture is probably not enough to destabilize the slope and cause flow of the surface material (Kossacki and Markiewicz, 2004).

Recent modeling of snowpacks on Mars by Williams and Toon (2006) find that (1) snowpacks on Mars sublime away very quickly and (2) if melting temperatures are reached within the snowpack, it is only for few $\mathrm{cm}$ of remaining snow, which would only generate a tiny amount of runoff (should it melt). Their results suggest that a $10 \mathrm{~m}$ thick dirty snowpack of moderate density $\left(550 \mathrm{~kg} / \mathrm{m}^{3}\right)$ and albedo $(0.21)$ would sublime in less than five years. A cleaner snow-pack would sublime in less than 20 years. In addition, snowpack temperatures never reach the melting point, raising serious questions regarding the availability of runoff for gully incision.

Based on the combination of observational data and numerical modeling results we therefore conclude that the snowmelt model could be possible but is not the most likely explanation for the origin of the martian gullies.

\subsection{Deep liquid water aquifer}

Gaidos (2001) suggested that the martian gullies might derive their water from a deep subsurface source. There are several observational trends that can be tested using this model for gully formation. These lines of reasoning are also explained in Heldmann and Mellon (2004) and are summarized here in light of our new observations.

\subsubsection{Latitudinal distribution}

The deep aquifer model predicts that gullies should only be found poleward of $30^{\circ}$ because (1) the cryosphere is too thin closer to the equator and will not impinge on the underlying water to form a confined aquifer against the basement rock and (2) an aquifer can become desiccated at lower latitudes where ground ice is unstable. These arguments explain why gullies are found poleward of $30^{\circ} \mathrm{N}$ but do not explain the increase in gully occurrence between $30^{\circ}-45^{\circ} \mathrm{N}$ and the subsequent decline in the number of gullies as one moves closer to the pole from $45^{\circ} \mathrm{N}$ as shown in Fig. 3 .

Second, it is hypothesized that gullies form when water from a sill erupts onto the martian surface to release the liquid water.
The water stops moving upwards in the fracture or fissure and forms a sill where the horizontal normal stress exceeds the vertical normal stress. However, it is unclear why sills would erupt onto the surface only on specific terrains such as the walls of impact craters, valleys, pits, and graben as opposed to flatter surfaces. Water that moves upwards where there is flat terrain overhead instead of steep-walled terrain should freeze in place. This freezing process could be manifested on the surface since the volume of water will undergo a $9 \%$ expansion as it freezes to ice. This model allows for a continuous supply of liquid water from the deep aquifer, and therefore raised, mounded structures formed by the near-surface freezing of a deep water supply might be expected on flatter terrain. Increased pressures induced from the water propagating upwards through the fracture which encounters a frozen sill could be great enough to exceed the vertical (overburden) stress, and so occasional outbursts of liquid water could theoretically be observed on flat terrain. Such features have not yet been observed on Mars but could be an intriguing area of future study.

\subsubsection{Alcove base depth}

Third, in this model the sills are predicted to form 100$1000 \mathrm{~m}$ below the surface due to low vertical stresses or failure of the surrounding rock. The depth of the sills should correlate with the observed depths of the gully alcoves since the sill represents the source region of the water. Therefore the predicted range in sill depth is broadly consistent with the observed alcove base depths although it is difficult at the present time to account for individual variations in alcove depth amongst various gully systems.

\subsubsection{Orientation}

Fourth, according to the deep aquifer model, gullies should show a preference for poleward facing slopes closer to the equator whereas this preference should diminish at latitudes closer to the pole. Gullies would tend to form on the colder slopes because an ice-saturated regolith would allow for easier horizontal propagation of the sill or dike compared to a dry, incompetent regolith. On the Sun-facing slopes water will not reach the surface but instead will seep back into the dry, desiccated regolith. This prediction is not fully in agreement with the observations as shown in Fig. 7 since the majority of gullies overall are on equator-facing slopes. However, the distribution of gullies between equator-facing and pole-facing orientations is most evenly distributed within the highest latitude band $\left(58^{\circ}-72^{\circ} \mathrm{N}\right)$ which may suggest that a preference for equator-facing versus pole-facing orientation is lessened closer to the pole. Given all the observational data, we conclude that a deep aquifer source feeding each gully system is possible, although not all of the observations can be explained by this model.

All of the proposed mechanisms of gully formation previously discussed are listed in Table 2 and compared with several lines of observational evidence as gathered from this work. Based on an analysis of predicted trends of each model, we determine if the predictions conform to each observation to assess the relative validity of each model. The shallow aquifer (Mellon and Phillips, 2001), deep aquifer (Gaidos, 2001), and 
Table 2

Summary of proposed mechanisms of gully formation and observational constraints used to test each model

\begin{tabular}{|c|c|c|c|c|c|c|c|c|}
\hline & & \multicolumn{7}{|c|}{ Observational constraints } \\
\hline & & Morphology & $\begin{array}{l}\text { Subsurface } \\
\text { temperature } \\
\text { regime }\end{array}$ & $\begin{array}{l}\text { Latitudinal } \\
\text { distribution }\end{array}$ & Orientation & $\begin{array}{l}\text { Alcove } \\
\text { depth }\end{array}$ & Slope angle & $\begin{array}{l}\text { Overall } \\
\text { potential }\end{array}$ \\
\hline Model & Reference & $\begin{array}{l}\text { Sinuous and } \\
\text { V-shaped } \\
\text { channels } \\
\text { consistent with } \\
\text { fluid erosion, } \\
\text { continuous } \\
\text { alcove and } \\
\text { channel }\end{array}$ & $\begin{array}{l}\text { Calculated } \\
\text { subsurface } \\
\text { temperature at } \\
\text { depth of } \\
\text { observed alcoves } \\
\text { based on a range } \\
\text { of thermal } \\
\text { conductivities }\end{array}$ & $\begin{array}{l}\text { Relative number } \\
\text { of MOC images } \\
\text { containing } \\
\text { gullies at } \\
\text { latitudes } \\
\text { between } \\
30^{\circ}-72^{\circ} \mathrm{S}\end{array}$ & $\begin{array}{l}\text { Preferred } \\
\text { orientation of } \\
\text { gully systems } \\
\text { with respect to } \\
\text { geographic pole } \\
\text { as a function of } \\
\text { latitude }\end{array}$ & $\begin{array}{l}\text { Depth } \\
\text { to gully } \\
\text { alcove } \\
\text { measured } \\
\text { with } \\
\text { respect to } \\
\text { overlying } \\
\text { ridge }\end{array}$ & $\begin{array}{l}\text { Incline angle } \\
\text { for observed } \\
\text { gully } \\
\text { alcoves }\end{array}$ & \\
\hline $\begin{array}{l}\text { Carbon } \\
\text { dioxide }\end{array}$ & $\begin{array}{l}\text { Musselwhite et } \\
\text { al. (2001) }\end{array}$ & No & No & No & No & No & N/A & Low \\
\hline $\begin{array}{l}\text { Shallow } \\
\text { aquifer }\end{array}$ & $\begin{array}{l}\text { Mellon and } \\
\text { Phillips (2001) }\end{array}$ & Yes & Yes & Yes & No & Yes & N/A & High \\
\hline $\begin{array}{l}\text { Melting } \\
\text { ground ice }\end{array}$ & $\begin{array}{l}\text { Costard et al. } \\
(2002) \text {, } \\
\text { Gilmore and } \\
\text { Phillips (2002) }\end{array}$ & Yes & N/A & No & No & No & N/A & Low \\
\hline $\begin{array}{l}\text { Geothermal } \\
\text { heating }\end{array}$ & $\begin{array}{l}\text { Hartmann } \\
(2001)\end{array}$ & Yes & Yes & Maybe & No & Yes & N/A & High \\
\hline Landslide & Treiman (2003) & No & N/A & No & No & No & No & Low \\
\hline Snowmelt & $\begin{array}{l}\text { Christensen } \\
(2003)\end{array}$ & Yes & N/A & No & No & No & N/A & Low \\
\hline Deep aquifer & Gaidos (2001) & Yes & Yes & No & No & Maybe & N/A & High \\
\hline
\end{tabular}

geothermal heating (Hartmann, 2002) hypotheses most adequately conform to the observational tests listed in Table 2 whereas the carbon dioxide (Musselwhite et al., 2001), melting ground ice (Costard et al., 2002), dry landslide (Treiman, 2003), and snowmelt (Hartmann, 2002; Lee et al., 2002; Christensen, 2003; Lee et al., 2006) hypotheses are the most unlikely explanations for the origin of the martian gullies. No model perfectly explains all of the observations, but overall the gullies seem intimately tied to subsurface phenomenon as opposed to atmospheric phenomenon such as wind deposition of sediment or snowfall.

\section{Summary}

We have analyzed 137 MOC images containing clear evidence of recent gully activity on Mars between $30^{\circ} \mathrm{N}$ and $90^{\circ} \mathrm{N}$ using MOC, MOLA, and TES data. We have reported and analyzed trends in the dimensional and physical properties of the northern hemisphere gullies and their surrounding terrain and compared these findings with data gleaned from a study of the southern hemisphere gullies. We find that the number of gully systems rises between $30^{\circ}-45^{\circ} \mathrm{N}$ and then tends to taper off at higher latitudes. Also, the gully alcove bases occur typically within the first several hundred meters of the overlying ridge. Additionally, northern hemisphere gullies are found on all slope orientations at all latitudes but are preferentially found on equatorward facing slopes. Using thermal conductivities derived from TES surface measurements as well as modeled surface temperatures and assuming a dry overburden soil, we find that $95 \%$ of the gully alcove bases lie at depths where subsurface temperatures could be greater than $273 \mathrm{~K}$ and $5 \%$ of the alcove bases lie within the solid water regime. A low conductivity overburden results in temperatures above $273 \mathrm{~K}$ for all of the alcove bases which suggests that liquid water could exist in a shallow aquifer at these depths to carve the gully features. Assuming an icy overburden soil, all of the alcove bases lie within the temperature-pressure regime of solid $\mathrm{CO}_{2}$ and it is not possible for all of the alcove bases to be located within the liquid regime, implying that $\mathrm{CO}_{2}$ is not the most likely agent of erosion in comparison with liquid water.

No model yet proposed explains all of the observed gully features, but based on the data we can place additional constraints on future models. In general, the subsurface water sources are more consistent with the observations than the surface water, near-surface water, and any carbon dioxide models. We find that the carbon dioxide, melting ground ice, dry landslide, and snowmelt models inadequately conform to the MGS observations and are the least likely mechanisms of gully formation proposed to date. Although the shallow aquifer, geothermal heating, and deep aquifer models do not explain all of the MGS observations, these models remains as the most viable theories to explain the origin of the martian gullies.

Findings reported here pertaining to the northern hemisphere gullies are generally consistent with findings previously reported for the southern hemisphere gullies (Heldmann and Mellon, 2004). Northern hemisphere gullies appear more eroded and sometimes show evidence of superposed impact craters, suggesting a possibly older age than their southern hemisphere counterparts. However, gullies in both the north and the south appear to be intrinsically similar and likely were created by similar formation mechanisms. Since data from this study of northern hemisphere gullies is not inconsistent with 
data previously published for gullies in the southern hemisphere (Heldmann and Mellon, 2004), conclusions reached for the southern hemisphere analysis (Heldmann and Mellon, 2004) are supported by this northern hemisphere data. We note, however, that taken alone, the northern hemisphere data supports these conclusions less concretely than the southern hemisphere dataset.

\section{Acknowledgments}

The authors wish to thank Eric Hieronymus for his assistance in analyzing the MOLA and TES data. Thanks also to Malin Space Science Systems for publicly-available MOC imagery at MSSS.com. We also thank Shane Byrne and an anonymous reviewer for their thoughtful reviews of this work which has greatly helped to improve the quality of this paper.

\section{References}

Balme, M., Mangold, N., Baratoux, D., Costard, F., Gosselin, M., Masson, P., Pinet, P., Heukum, G., 2006. Orientation and distribution of recent gullies in the southern hemisphere of Mars: Observations from High Resolution Stereo Camera/Mars Express (HRSC/MEX) and Mars Orbiter Camera/Mars Global Surveyor (MOC/MGS) data. J. Geophys. Res. 111 (E5), doi:10.1029/2005JE002607.

Berman, D.C., Hartmann, W.C., Crown, D.A., Baker, V.R., 2005. The role of arcuate ridges and gullies in degradation of craters in the Newton Basin of Mars. Icarus 178, 465-486.

Brass, G.W., 1980. Stability of brines on Mars. Icarus 42, 20-28.

Bridges, N.T., Hecht, M.H., 2002. Mars polar gully modification and possible formation from condensed volatiles. Eos 83 (Fall Suppl.), 47

Carr, M.H., Crumpler, L.S., Cutts, J.A., Greeley, R., Guest, J.E., Masursky, H., 1977. Martian impact craters and emplacement of ejecta by surface flow. J. Geophys. Res. 82, 4055-4065.

Christensen, P.R., 2003. Formation of recent martian gullies through melting of extensive water-rich snow deposits. Nature 422, 45-48.

Clow, G.D., 1987. Generation of liquid water on Mars through the melting of a dusty snowpack. Icarus 72, 95-127.

Costard, F., Forget, F., Mangold, N., Peulvast, J.P., 2002. Formation of recent martian debris flows by melting of near-surface ground ice at high obliquity. Science 295, 110-113.

Davies, G.F., Arvidson, R.E., 1981. Martian thermal history, core segregation, and tectonics. Icarus 45, 339-346.

Edgett, K.S., Malin, M.C., Williams, R.M.E., Davis, S.D., 2003. Polar and middle-latitude martian gullies: A view from MOC-MGS after two years in the mapping orbit. Lunar Planet. Sci. XXXIV. Abstract 1038.

Fanale, F.P., 1976. Martian volatiles: Their degassing history and geochemical fate. Icarus 28, 179-202.

Farouki, O.T., 1986. Thermal properties of soils. Ser. Rock Soil Mech. 11, 1136.

Franck, S., Orgzall, I., 1987. A new view of martian evolution. Earth Moon Planets 37, 287-313.

Gaidos, E.J., 2001. Cryovolcanism and the recent flow of liquid water on Mars. Icarus 153, 218-223.

Gilmore, M.S., Phillips, E.L., 2002. The role of aquicludes in the formation of the martian gullies. Geology 30, 1107-1110.

Haberle, R.M., McKay, C.P., Schaeffer, J., Cabrol, N.A., Grin, E.A., Zent, A.P., Quinn, R.M., 2001. On the possibility of liquid water on present-day Mars. J. Geophys. Res. 106 (E10), 23317-23326.

Hartmann, W.K., 2001. Martian seeps and their relation to youthful geothermal activity. Space Sci. Rev. 96, 405-410.

Hartmann, W.K., 2002. Comparison of Icelandic and martian gullies. Lunar Planet. Sci. XXXIII. Abstract 1904
Hartmann, W.K., Berman, D.C., 2000. Elysium Planitia lava flows: Crater count chronology and geological implications. J. Geophys. Res. 105, 1501115026.

Hartmann, W.K., Neukum, G., 2001. Cratering chronology and the evolution of Mars. Space Sci. Rev. 96, 165-194.

Hartmann, W.K., Thorsteinsson, T., Sigurdsson, F., 2003. Martian hillside gullies and Icelandic analogs. Icarus 162, 259-277.

Hecht, M.H., 2002. Metastability of liquid water on Mars. Icarus 156, 373-386.

Heldmann, J.L., Mellon, M.T., 2004. Observations of martian gullies and constraints on potential formation mechanisms. Icarus 168, 285-304.

Heldmann, J.L., Mellon, M.T., Toon, O.B., 2004. Martian gully features in various geologic settings and implications for formation processes. Int. J. Astrobiol., doi:10.1017/S14735500404001648, 83.

Heldmann, J.L., Johansson, H., Carlsson, E., Mellon, M.T., 2005a. Northern hemisphere gullies on Mars: Analysis of spacecraft data and implications for formation mechanisms. Lunar Planet. Sci. XXXVI. Abstract 1271.

Heldmann, J.L., Toon, O.B., Pollard, W.H., Mellon, M.T., Pitlick, J., McKay, C.P., Andersen, D.T., 2005b. Formation of martian gullies by the action of liquid water flowing under current martian environmental conditions. J. Geophys. Res. 110, doi:10.1029/2004JE002261.

Howard, A.D., 2003. Tongue ridges and rumpled crater floors in mid-southernlatitude martian craters. Lunar Planet. Sci. XXXIV. Abstract 1065.

Johnston, D.H., McGetchin, T.R., Toksoz, M.N., 1974. The thermal state and internal structure of Mars. J. Geophys. Res. 79, 3959-3971.

Kirk, R.L., Archinal, B.A., Lee, E.M., Davies, M.E., Colvin, T.R., Duxbury, T.C., 2001a. Global digital image mosaics of Mars: Assessment of geodetic accuracy. Lunar Planet. Sci. XXXII. Abstract 1856.

Kirk, R.L., Becker, T.L., Eliason, E.M., Anderson, J., Soderblom, L.A., 2001 b. Geometric calibration of the Mars Orbiter Cameras and coalignment with the Mars Orbiter Laser Altimeter. Lunar Planet. Sci. XXXII. Abstract 1863.

Knauth, L.P., Burt, D.M., 2002. Eutectic brines on Mars: Origin and possible relation to young seepage features. Icarus 158, 267-271.

Kossacki, K.J., Markiewicz, W.J., 2004. Seasonal melting of surface water ice condensing in martian gullies. Icarus 171, 272-283.

Kravchenko, Y.G., Krupskii, I.N., 1986. Thermal conductivity of solid $\mathrm{N}_{2} \mathrm{O}$ and $\mathrm{CO}_{2}$. Sov. J. Low Temp. Phys. 12, 46-48.

Lee, P., McKay, C.P., Matthews, J., 2002. Gullies on Mars: Clues to their formation timescale from possible analogs from Devon Island, Nunavut, Arctic Canada. Lunar Planet. Sci. XXXIII. Abstract 2050.

Lee, P., Glass, B.J., Osinski, G.R., Parnell, J., Schutt, J.W., McKay, C.P., 2006. Gullies on Mars: Fresh gullies in dirty snow, Devon Island, High Arctic, as end-member analogs. Lunar Planet. Sci. XXXVII. Abstract 251.

Malin, M.C., Edgett, K.S., 2000. Evidence for recent groundwater seepage and surface runoff on Mars. Science 288, 2330-2335.

Malin, M.C., Edgett, K.E., 2001. Mars Global Surveyor Mars Orbiter Camera: Interplanetary cruise through primary mission. J. Geophys. Res. 106, 23429-23570.

Mellon, M.T., 1997. Thermal contraction cracks in martian permafrost: Implications for small-scale polygonal features. Lunar Planet. Sci. XXVIII. Abstract 1495.

Mellon, M.T., Jakosky, B.M., 1995. The distribution and behavior of martian ground ice during past and present epochs. J. Geophys. Res. 100 (E6), 11781-11799.

Mellon, M.T., Phillips, R.J., 2001. Recent gullies on Mars and the source of liquid water. J. Geophys. Res. 106, 23165-23179.

Mellon, M.T., Jakosky, B.M., Kieffer, H.H., Christensen, P.R., 2000. Highresolution thermal inertia mapping from the Mars Global Surveyor Thermal Emission Spectrometer. Icarus 148, 437-455.

Mellon, M.T., Kretke, K.A., Smith, M.D., Pelkey, S.M., 2002. A global map of thermal inertia from Mars Global Surveyor mapping mission data. Lunar Planet. Sci. XXXIII. Abstract 1416.

Musselwhite, D.S., Swindle, T.D., Lunine, J.I., 2001. Liquid $\mathrm{CO}_{2}$ breakout and the formation of recent small gullies on Mars. Geophys. Res. Lett. 28, 1283-1285.

Nyquist, K., Bogard, D., Shih, C., Greshake, A., Stoeffler, D., Eugster, O., 2001. Ages and geologic histories of martian meteorites. Space Sci. Rev. 96, 105164.

Presley, M.A., Christensen, P.R., 1997. Thermal conductivity measurements of particulate materials. 2. Results. J. Geophys. Res. 102, 6551-6566. 
Ritter, D.F., Kochel, R.C., Miller, J.R., 1978. Process Geomorphology. Wm. C. Brown Publishers, Dubuque, IA.

Schubert, G., Spohn, T., 1990. Thermal history of Mars and the sulfur content of its core. J. Geophys. Res. 95, 14095-14104.

Spohn, T., 1991. Mantle differentiation and thermal evolution of Mars, Mercury, and Venus. Icarus 90, 222-236.

Stevenson, D.J., Spohn, T., Schubert, G., 1983. Magnetism and thermal evolution of the terrestrial planets. Icarus 54, 466-489.

Stewart, S.T., Nimmo, F., 2002. Surface runoff features on Mars: Testing the carbon dioxide formation hypothesis. J. Geophys. Res. 107, doi:10.1029/ 2000JE001465.

Sullivan, R., Thomas, P., Veverka, J., Malin, M., Edgett, K.S., 2001. Mass movement slope streaks imaged by the Mars Orbiter Camera. J. Geophys. Res. 106, 23607-23633.

Toksoz, M.N., Hsui, A.T., 1978. Thermal history and evolution of Mars. Icarus 34, 537-547.
Toksoz, M.N., Hsui, A.T., Johnston, D.H., 1978. Thermal evolution of the terrestrial planets. Moons Planets 18, 281-320.

Treiman, A.H., 2003. Geologic settings of martian gullies: Implications for their origins. J. Geophys. Res. 108, doi:10.1029/2002JE001900.

Weast, R.C.E. (Ed.), 1986. CRC Handbook of Chemistry and Physics. CRC Press, Boca Raton, FL, p. 82.

Williams, K.E., Toon, O.B., 2006. Stability of mid-latitude snowpacks on Mars. Lunar Planet. Sci. XXXVII. Abstract 1201.

Wohletz, K.H., Sheridan, M.F., 1983. Martian rampart crater ejectaExperiments and analysis of melt-water interaction. Icarus 56, 15-37.

Yoshikawa, K., 2000. Contraction cracking and ice wedge polygons in Mars. In: Mars Polar Science Conference, Reykjavik, Iceland. Abstract 4045.

Zuber, M.T., Smith, D.E., Solomon, S.C., Muhleman, D.O., Head, J.W., Garvin, J.B., Abshire, J.B., Bufton, J.L., 1992. The Mars Observer Laser Altimeter investigation. J. Geophys. Res. 97, 7781-7797. 